\title{
Structure and function of oxide nanostructures: catalytic consequences of size and composition
}

\author{
Josef Macht and Enrique Iglesia* \\ Received 28th March 2008, Accepted 27th May 2008 \\ First published as an Advance Article on the web 9th July 2008 \\ DOI: $10.1039 /$ b805251d
}

Redox and acid-base properties of dispersed oxide nanostructures change markedly as their local structure and electronic properties vary with domain size. These changes give rise to catalytic behavior, site structures, and reaction chemistries often unavailable on bulk crystalline oxides. Turnover rates for redox and acid catalysis vary as oxide domains evolve from isolated monomers to two-dimensional oligomers, and ultimately into clusters with bulk-like properties. These reactivity changes reflect the ability of oxide domains to accept or redistribute electron density in kinetically-relevant reduction steps, in the formation of temporary acid sites via reductive processes, and in the stabilization of cationic transition states. Reduction steps are favored by low-lying empty orbitals prevalent in larger clusters, which also favor electron delocalization, stable anions, and strong Brønsted acidity. Isomerization of xylenes and alkanes, elimination reactions of alkanols, and oxidation of alkanes to alkenes on $\mathrm{V}, \mathrm{Mo}, \mathrm{Nb}$, and $\mathrm{W}$ oxide domains are used here to demonstrate the remarkable catalytic diversity made available by changes in domain size. The reactive and disordered nature of small catalytic domains introduces significant challenges in their synthesis and their structural and mechanistic characterization, which require in situ probes and detailed kinetic analysis. The local structure and electronic properties of these materials must be probed during catalysis and their catalytic function be related to specific kinetically-relevant steps. Structural uniformity can be imposed on oxide clusters by the use of polyoxometalate clusters with thermodynamically stable and well-defined size and connectivity. These clusters provide the compositional diversity and the structural fidelity required to develop composition-function relations from synergistic use of experiments and theory. In these clusters, the valence and electronegativity of the central atom affects the acid strength of the polyoxometalate clusters and the rate constants for acid catalyzed elementary steps via the specific stabilization of cationic transition states in isomerization and elimination reactions.

Department of Chemical Engineering, University of California, Berkeley, CA, USA.E-mail: iglesia@berkeley.edu; Fax: 510-642-4778; Tel: 510-642-9673

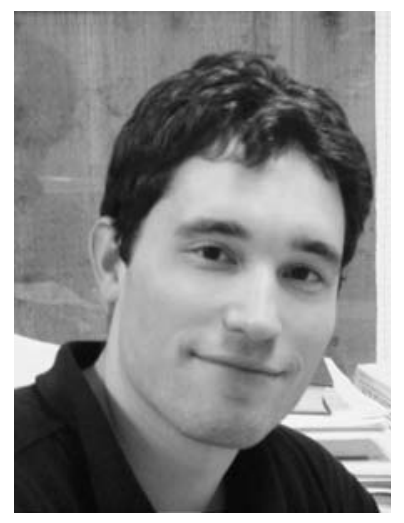

Josef Macht
Josef Macht received his Diploma in Chemical Engineering at the Technical University of Munich in 2003. Since then, he has been involved in the study of acidcatalyzed rearrangements of hydrocarbons and alcohols on solid acids as part of his doctoral research in the Department of Chemical Engineering at the University of California at Berkeley. His research brings together experimental and theoretical approaches to elucidate the mechanism and structural requirements for selective rearrangements of organic molecules on active surfaces in inorganic solids.

\section{Introduction}

The structure, electronic properties, and catalytic function of small oxide domains depend sensitively on their size and

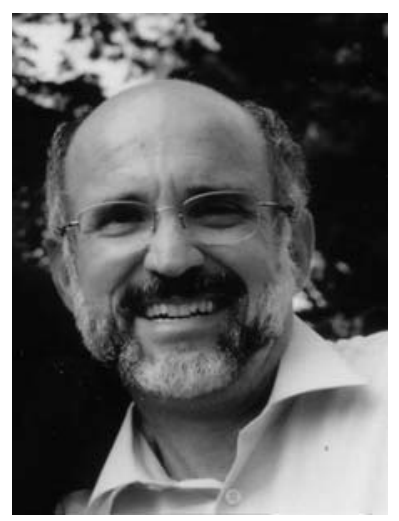

Enrique Iglesia
Enrique Iglesia is Chancellor Professor of Chemical Engineering at the University of California, Berkeley, a Faculty Scientist at the E. $O$. Lawrence Berkeley National Laboratory, and the Director of the Berkeley Catalysis Center. He is Editor-in-Chief of the Journal of Catalysis and a member of the National Academy of Engineering. His research group addresses the synthesis and structural and functional assessment of inorganic solids useful as catalysts

for chemical reactions relevant to energy conversion, synthesis of fuels and petrochemicals, and prevention or remediation of environmental impact. 
dimensionality, on their composition, and on their specific connectivity to less active oxides typically used as supports. ${ }^{1-5}$ Here, we examine these effects in the context of acid and oxidation reactions, two chemistries that share more than their catalysis by metal oxides. In fact, both types of reactions require that oxide domains accept electron density to form active Brønsted sites ${ }^{3}$ and to stabilize activated complexes ${ }^{4}$ in steps that often limit rates for such reactions.

The number of compositions of matter is restricted by possible combinations of elements. Their stable crystalline forms are constrained further by thermodynamics, through the relative energies of chemical bonds in inorganic structures, and by the stability of accessible crystallographic forms and structural motifs. For any ensemble of elements, however, changes in domain size provide functional and structural diversity without the need for changes in composition. Small structures may, in fact, remove crystallographic constraints pervasive in bulk crystalline structures. We expect, and typically find, that changes in the size and dimensionality of oxide domains give rise to electronic properties, atomic connectivities, and surface chemistries unavailable on crystalline oxides.

Clearly, the function of inorganic solids changes as we alter their domain size, as shown by the evolution of electronic and optical properties in semiconductors with changes in domain size, which allow the tuning of band gaps for a given composition in quantum dot devices. $^{6-8}$ These quantum confinement effects reflect the effect of size on the ability of semiconducting domains to delocalize electron density; in fact, their band gaps (or HOMOLUMO gaps) increase as domains become smaller. ${ }^{7}$ The surfaces of quantum dots are typically passivated with adsorbed organic moieties to stabilize their size, structure, and composition upon contact with ambient air. Their structures can be accurately assessed by microscopy and diffraction, which give clear micrographs and relatively sharp lines because of the crystalline nature and modest size $(5-10 \mathrm{~nm})$ of these electronic devices.

Catalytic reaction rates, rate constants for kinetically-relevant steps, and selectivities also change markedly as a given inorganic material is treated thermally using protocols that alter the size of the active oxide domains. ${ }^{1,3,5}$ These changes can be attributed to electronic modifications in less direct ways than for confined quantum structures in electronic devices. The size and local structure of inorganic domains useful as catalysts are seldom detectable by methods that probe long-range order, such as X-ray diffraction, or even by high-resolution transmission electron microscopy. Catalytic structures have reactive surfaces, as befits their role as catalysts, and their structures often change during catalysis in striking ways. These catalytic domains are also very small, often containing only a few atoms. Yet, as we move from crystalline oxides to oligomers and ultimately to isolated monomers, we have found, almost without exception, marked consequences for the surface chemistry and the catalytic function of metal oxides. ${ }^{1-5,9-12}$

The synthesis of these small catalytic structures presents significant challenges, but emerging methods have exploited the anchoring of oxo-ions on hydroxylated surfaces and the thermodynamic tendency of oxides to spread on other oxide surfaces ${ }^{13}$ to form dispersed oxide domains. The structural assessment of these domains is even more challenging, especially when we aim to probe accessibility, atomic connectivity, and local structure, the features relevant for catalytic function. The dearth of microscopy and diffraction evidence for structure and the frequent requirement that structure be assessed within reactive environments have directed characterization efforts towards spectroscopies based on photons, because of their ability to probe through relevant fluids and porous solids. Spectroscopic methods that probe complementary details about connectivity and bonding (Raman), electronic properties (UV-visible) and oxidation state and local coordination (X-ray absorption) have proven particularly useful. These methods invariably give ensemble-averaged spectral data because of the non-uniform structures prevalent in typical dispersed oxides. Only when inorganic structures are uniform, often because of strong thermodynamic preferences during synthesis (e.g. in Keggin polyoxometalate clusters), these methods allow unique and rigorous interpretations of local structure and connectivity. Keggin-type polyoxometalate clusters provide structural motifs and sizes that remain unchanged as composition changes. Their uniform size and diverse composition make them ideal to elucidate the effects of composition on catalytic function using experiments and quantumchemical methods.

This account describes our recent findings within the context of the work of others. It includes representative examples of the marked effects of the size of dispersed oxide domains and of the composition of Keggin-type polyoxometalate clusters on reactivity in acid catalysis (isomerization and elimination reactions) and in oxidation reactions. We do not aim to provide a comprehensive review of the extensive literature, but strive instead to describe some of the more general concepts required to understand the catalytic chemistry of small oxide domains, using the chosen examples, but with the aim to remain relevant to acid and oxidation catalysis in general.

Spectroscopic and catalytic data indicate that the ability of oxide domains to accept electron density increases with domain size. These changes bring forth, in turn, marked consequences for turnover rates and selectivity, because stoichiometric reduction events either lead to the generation of Brønsted acid sites or because reduction events are required for the stabilization of transition states in rate-determining $\mathrm{C}-\mathrm{H}$ bond activation steps in alkane oxidation. These reduction events benefit from clusters with low lying empty orbitals. The size of domains or clusters is also important in acid catalysis because the formation of cationic transition states requires the redistribution of electron density from $\mathrm{O}-\mathrm{H}$ bonds that act as Brønsted acid sites to anionic oxide clusters. The stability of the anion increases as the electron density derived from heterolytic cleavage of the $\mathrm{O}-\mathrm{H}$ bond is dispersed over larger or more electronegative clusters. These connections between acid and redox catalysis and between electronic and catalytic properties of oxide domains have been seldom discussed, but they are, albeit retrospectively, straightforward and unsurprising.

\section{Acid catalysis on dispersed tungsten oxide domains}

Acids catalyze chemical reactions by stabilizing cationic transition states, typically present in organic reactions as carbenium or carbonium ions. Strong acids and stable cationic transition states require a weak conjugate base (a stable 
anionic species) as part of ion-pairs involved in the activated complexes. Such stable anions often require cooperativity among acid molecules, even in the liquid phase, as in the association of $\mathrm{H}_{2} \mathrm{SO}_{4}$ molecules in concentrated sulfuric acid, ${ }^{14}$ which is sensitively disrupted by dilution with water, even at low concentrations. The negative charge required to form cationic intermediates or transition states is stabilized by metal-oxo domains in solid acids. Thus, the ability of oxide domains to redistribute charge is essential for their effectiveness in acid catalysis. In the case of neutral $\mathrm{WO}_{3}$ domains, the ability to accept additional electron density is even required for the formation of Brønsted acid sites.

$\mathrm{WO}_{x}$ domains dispersed on $\mathrm{ZrO}_{2}$ catalyze isomerization reactions at low temperatures. ${ }^{15-19}$ The isomerization of $o$-xylene involves protonation-deprotonation steps with intervening methyl shifts. ${ }^{20,21}$ These pathways do not require $\mathrm{H}_{2}$, either mechanistically or stoichiometrically. Yet, $o$-xylene isomerization rates on $\mathrm{WO}_{x}-\mathrm{ZrO}_{2}$ increased linearly with $\mathrm{H}_{2}$ pressure suggesting that $\mathrm{H}_{2}$ affects the density of active sites instead, as discussed in detail later. For a given $\mathrm{H}_{2}$ pressure, isomerization rates (per $\mathrm{W}$-atom) increased sharply and then decreased abruptly as the surface density of $\mathrm{WO}_{x}$ species on $\mathrm{ZrO}_{2}$ supports increased (Fig. 1). These rates did not depend on whether $\mathrm{WO}_{x}$ surface densities were varied by changing the amount of tungsten deposited onto $\mathrm{ZrO}_{2}$ supports (via impregnation with ammonium metatungstate) or by decreasing $\mathrm{ZrO}_{2}$ surface areas by thermal treatment after $\mathrm{WO}_{x}$ deposition. $^{1-3}$ The relevant catalytic function appears and then abruptly ceases as $\mathrm{ZrO}_{2}$ surfaces become increasingly covered by $\mathrm{WO}_{x}$ species.

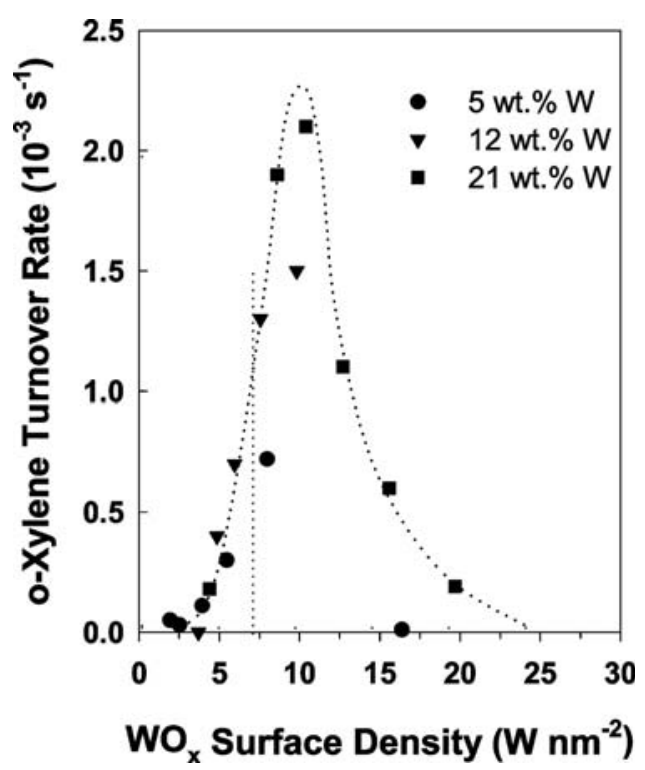

Fig. $1 o$-Xylene isomerization turnover rates (per $\mathrm{W}$-atom, $523 \mathrm{~K}$, $0.67 \mathrm{kPa} o$-xylene, $106 \mathrm{kPa} \mathrm{H}_{2}$ ) as a function of nominal $\mathrm{WO}_{x}$ surface density on three $\mathrm{WO}_{x}-\mathrm{ZrO}_{2}(5,12$, and $21 \mathrm{wt} \% \mathrm{~W})$ samples treated in air at $800 \mathrm{~K}$. The theoretical polytungstate monolayer capacity for $\mathrm{ZrO}_{2}\left(\sim 7 \mathrm{~W} \mathrm{~nm}^{-2}\right)$ is shown as a vertical dashed line. Reprinted from J. Catal., 181, D. G. Barton, S. L. Soled, G. D. Meitzner, G. A. Fuentes and E. Iglesia, Structural and catalytic characterization of solid acids based on zirconia modified by tungsten oxide, 57-72, Copyright 1999, with permission from Elsevier.

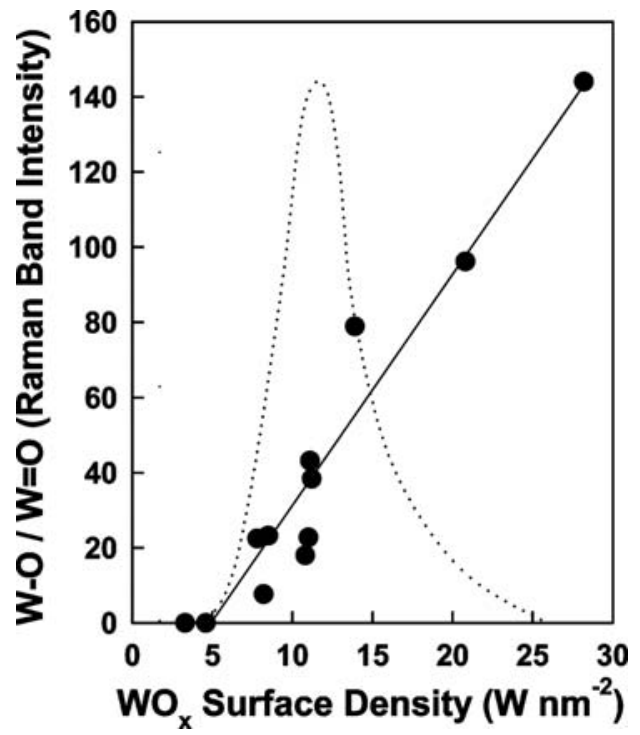

Fig. 2 Ratio of intensities for Raman bands at $807 \mathrm{~cm}^{-1}$ (W-O-W) and $1019 \mathrm{~cm}^{-1}$ (terminal $\mathrm{W}=\mathrm{O}$ ) as a function of nominal $\mathrm{WO}_{x}$ surface density for samples shown also in Fig. 1. The dashed curve represents a smooth fit through $o$-xylene isomerization rates (per $\mathrm{W}$ atom) in Fig. 1. Reproduced with permission from J. Phys. Chem. B, 1999, 103, 630-640. Copyright 1999 American Chemical Society.

Maximum rates (per $\mathrm{W}$ atom) were observed at $\mathrm{WO}_{x}$ surface densities of $\sim 10 \mathrm{~W} \mathrm{~nm}^{-2}$, which resemble those expected for two-dimensional polytungstate monolayers $\left(\sim 7 \mathrm{~W} \mathrm{~nm}^{-2}\right)$ from purely geometric arguments. The incipient detection of three-dimensional $\mathrm{WO}_{3}$ clusters by Raman and UV-visible spectroscopies (Fig. 2 and 3) at $\mathrm{WO}_{x}$ surface densities above $10 \mathrm{~W} \mathrm{~nm}^{-22}$ confirmed the highly dispersed nature of $\mathrm{WO}_{x}$

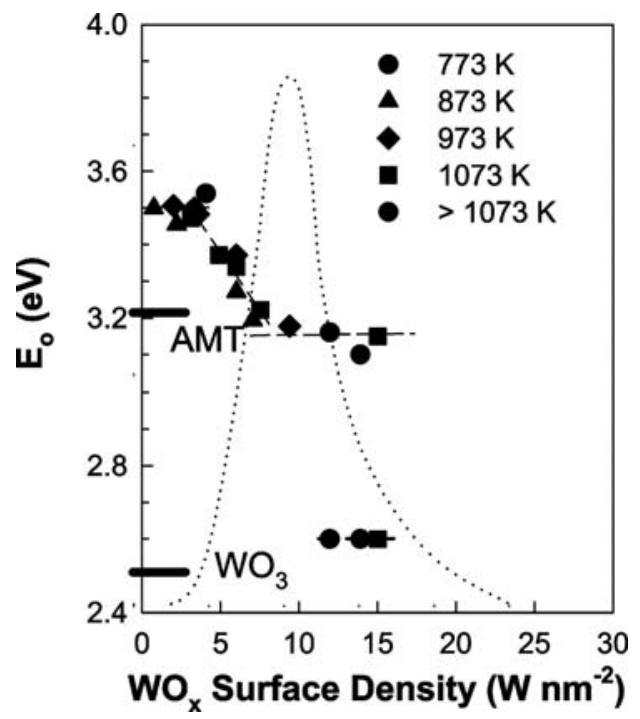

Fig. 3 Absorption edge energies of $\mathrm{WO}_{x}-\mathrm{ZrO}_{2}$ samples at several oxidation temperatures and tungsten contents. Two crystalline tungsten oxide materials (monoclinic $\mathrm{WO}_{3}$ and ammonium metatungstate) are shown as reference. The dashed curve represents a smooth fit through $o$-xylene isomerization rates (per $\mathrm{W}$ atom) in Fig. 1 [523 K, $0.66 \mathrm{kPa} o$-xylene, $100 \mathrm{kPa} \mathrm{H}_{2}$ ]. Reproduced with permission from $J$. Phys. Chem. B, 1999, 103, 630-640. Copyright 1999 American Chemical Society. 


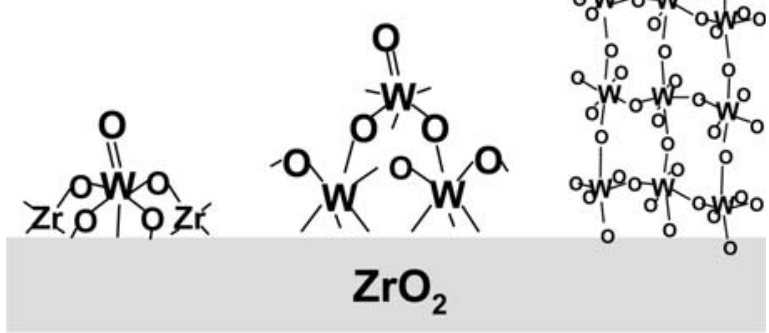

decreasing domain size and $W_{x} O_{x}$ surface density

Scheme 1 Structural evolution of supported $\mathrm{WO}_{x}$ domains from isolated monotungstates to two-dimensional polytungstate and three-dimensional $\mathrm{WO}_{3}$ clusters (note the increasing W-O-W connectivity with increasing extent of oligomerization).

domains at lower surface densities. Rates in Fig. 1 are normalized by the number of $\mathrm{W}$-atoms in each sample. Thus, the decrease in rates above $10 \mathrm{~W} \mathrm{~nm}^{-2}$ reflects, at least in part, the inaccessible nature of $\mathrm{WO}_{x}$ centers as three-dimensional $\mathrm{WO}_{3}$ clusters form. This abrupt decrease in rate also reflects the incipient formation of oxygen-deficient $\mathrm{WO}_{x}$ species (e.g. $\mathrm{WO}_{2.9}$ ), which cannot stabilize reactive $\mathrm{O}-\mathrm{H}$ groups because hydroxyl recombination leads to the desorption of $\mathrm{H}_{2} \mathrm{O}$ and become unreactive in acid-catalyzed reactions. ${ }^{3,10}$

We conclude that well-dispersed structures present at low $\mathrm{WO}_{x}$ surface densities $\left(<10 \mathrm{~W} \mathrm{~nm}^{-2}\right)$ become more reactive in acid catalysis with increasing domain size. This proposal suggests, in turn, that $\mathrm{W}-\mathrm{O}-\mathrm{W}$ connectivity, which emerges as isolated monotungstate species form two-dimensional oligomers, is essential to form the active sites or to stabilize the cationic transition states involved in $o$-xylene isomerization. Evidence for the structural evolution suggested by these data is provided by Raman spectra, which probe vibrations for terminal $\mathrm{W}=\mathrm{O}$ bonds, prevalent in well-dispersed $\mathrm{WO}_{x}$ domains, and for $\mathrm{W}-\mathrm{O}-\mathrm{W}$ linkages present in two-dimensional and three-dimensional extended $\mathrm{WO}_{x}$ oligomers (Scheme 1).

The relative intensities of vibrational modes at $807 \mathrm{~cm}^{-1}$ for $\mathrm{W}-\mathrm{O}-\mathrm{W}$ structures and at $1019 \mathrm{~cm}^{-1}$ for terminal $\mathrm{W}=\mathrm{O}$ bonds [2] change with increasing $\mathrm{WO}_{x}$ surface density in the manner expected from a monotonic increase in $\mathrm{W}-\mathrm{O}-\mathrm{W}$ connectivity with increasing surface coverage (Fig. 2). The ratio of $\mathrm{W}-\mathrm{O}-\mathrm{W}$ to $\mathrm{W}=\mathrm{O}$ band intensities increased almost linearly with $\mathrm{WO}_{x}$ surface density, consistent with an increase in domain size. As observed also for catalytic rates, this ratio did not depend on whether a given $\mathrm{WO}_{x}$ surface density was achieved by increasing $\mathrm{W}$ content or decreasing $\mathrm{ZrO}_{2}$ surface area (Fig. 2). We note that $o$-xylene isomerization rates, shown as a dashed curve in Fig. 2, became detectable only as the bands for $\mathrm{W}-\mathrm{O}-\mathrm{W}$ modes appeared in Raman spectra with increasing $\mathrm{WO}_{x}$ surface density.

The ubiquitous changes in optical and electronic properties of semiconductors with domain size suggest that changes in connectivity, dimensionality, and size with changes in $\mathrm{WO}_{x}$ surface density should give rise to concomitant shifts in the $\mathrm{UV}$-visible absorption spectrum of $\mathrm{WO}_{x}-\mathrm{ZrO}_{2}$ samples. The specific probing of the near-edge spectrum, first proposed by
Weber ${ }^{22}$ and Fournier et al., ${ }^{23}$ avoids the complex features and the energy-dependent scattering coefficients that plague quantitative interpretations of electronic processes leading to absorption features above the edge for inorganic solids.

The absorption edge energies in $\mathrm{WO}_{x}$ semiconductors reflect ligand-to-metal charge transitions (LMCT) from the highest occupied molecular orbitals (HOMO) in O-atoms to the lowest unoccupied molecular orbitals (LUMO) in W atoms. Thus, this gap, and specifically the LUMO energy, reflect the ability of W-centers to accommodate the electrons transferred upon reduction. Reduction processes are favored by low LUMO energy levels. $^{2,4,22,23}$ The electronic spectra of model $\mathrm{Mo}^{22}$ and $\mathrm{W}^{2}$ oxides with known structure but different cluster size and connectivity confirmed that larger and more intimately connected domains (edge-shared instead of corner-shared octahedra) give lower LMCT energies, consistent with more effective electron delocalization within larger $\mathrm{WO}_{x}$ domains in LMCT processes and with lower LUMO energies. The ubiquitous quantum confinement effects that lead to the observed decrease in LMCT energy with size reflect a decrease in particle-in-a-box quantum localization energy $\left(1 / \mathrm{R}^{2}\right.$ dependence) that is counterbalanced by a decrease in the Coulomb energy (1/R dependence) for electron-hole attractive interactions. ${ }^{24}$ The strength of these quantum size effects depends on the extent to which orbitals on two adjacent atomic centers interact and, as a result, on the structure and composition of a given semiconductor. The relative magnitude of changes in LMCT energy with size, and the domain size at which these changes appear, increase with decreasing effective electron mass. ${ }^{25}$ As a consequence, small band gap solids are more sensitive to domain size and exhibit detectable changes in electronic properties for larger domains than inorganic solids with larger band gaps.

Fig. 3 provides evidence for a monotonic evolution in electronic properties (and structure), as domains evolve from monotungstate species to two-dimensional polytungstates and ultimately to $\mathrm{WO}_{3}$ crystallites with increasing $\mathrm{WO}_{x}$ surface density. At surface densities below $4 \mathrm{~W} \mathrm{~nm}^{-2}$, the measured edge energy is high (3.49 $\pm 0.02 \mathrm{eV}$ ), insensitive to surface density, and smaller than in isolated tetrahedral $\mathrm{WO}_{4}{ }^{2-}$ anions solvated by aqueous media $(\sim 5 \mathrm{eV})$. Absorption energies decreased linearly from $3.49 \mathrm{eV}$ to $3.16 \mathrm{eV}$, as the $\mathrm{WO}_{x}$ surface density increased from 4 to $\sim 7 \mathrm{~W} \mathrm{~nm}^{-2}$ and then remained constant at $3.16 \pm 0.05 \mathrm{eV}$ above $8 \mathrm{~W} \mathrm{~nm}^{-2}$. In this latter region, a second absorption edge gradually emerged at $2.6 \mathrm{eV}$, which corresponds to the band gap for crystalline $\mathrm{WO}_{3}$. The intensity of this second edge feature increased monotonically with increasing $\mathrm{WO}_{x}$ surface density, as expected from the increasing abundance of bulk $\mathrm{WO}_{3}$ with increasing surface density.

The constant edge energy observed at low surface densities indicates that $\mathrm{WO}_{x}$ species remain electronically isolated from each other at these surface densities. Intimate contact with $\mathrm{ZrO}_{2}$, however, led to edge energies smaller than for solvated monotungstate species. The subsequent decrease in edge energies with surface coverage reflects the formation of interconnected two-dimensional oligomers. Catalytic rates became detectable as absorption energies start to decrease with increasing surface density, indicating that oligomeric species provide the reactive surfaces required for $o$-xylene isomerization catalysis. 


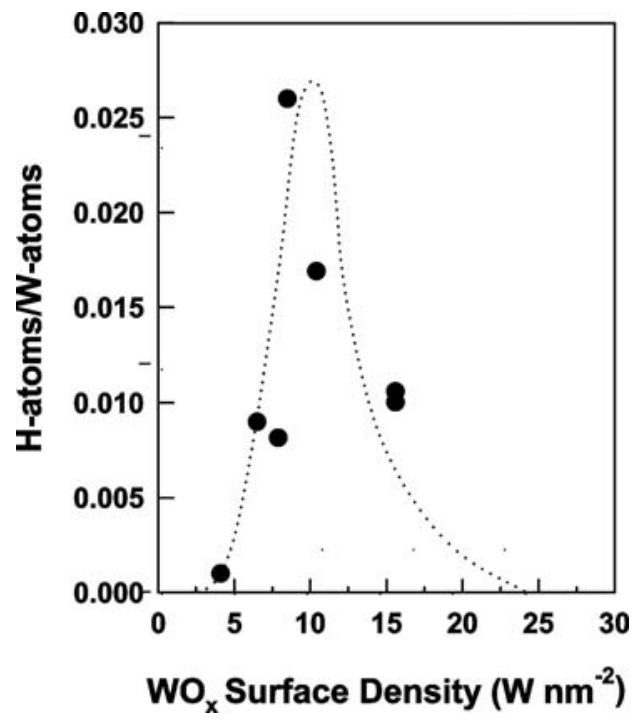

Fig. 4 Reversible $\mathrm{H}_{2}$ uptakes at $523 \mathrm{~K}$ and $45 \mathrm{kPa} \mathrm{H}$ on $\mathrm{WO}_{x}-\mathrm{ZrO}_{2}$ samples oxidized at $1073 \mathrm{~K}$, reduced in $\mathrm{H}_{2}$ at $523 \mathrm{~K}$ for $1 \mathrm{~h}$, and evacuated at $523 \mathrm{~K}$, plotted together with a smooth fit through $o$-xylene isomerization rates (per W atom) in Fig. 1 as a function of $\mathrm{WO}_{x}$ surface density. Reprinted from J. Catal., 181, D. G. Barton, S. L. Soled, G. D. Meitzner, G. A. Fuentes and E. Iglesia, Structural and catalytic characterization of solid acids based on zirconia modified by tungsten oxide, 57-72, Copyright 1999, with permission from Elsevier.

The constant value of the absorption energy at intermediate $\mathrm{WO}_{x}$ surface densities $(3.16 \pm 0.05 \mathrm{eV})$ resembles that for solvated $\mathrm{W}_{12}$ isopolytungstate clusters (e.g. ammonium metatungstate; AMT, Fig. 3) and $\mathrm{W}_{12}$ heteropolytungstate Keggin clusters [2]. Crystalline $\mathrm{WO}_{3}$ species were first detected in the Raman and electronic spectra at surface densities similar to those expected for two-dimensional polytungstate monolayers on $\mathrm{ZrO}_{2}$. We note that the $\mathrm{WO}_{x}-\mathrm{ZrO}_{2}$ edge energies coalesce into a single curve as a function of surface density, whether the surface density was achieved by varying $\mathrm{W}$-content or the $\mathrm{ZrO}_{2}$ surface area, as also observed for $o$-xylene isomerization rates and Raman spectra.

These spectroscopic methods confirm the structural evolution expected as $\mathrm{WO}_{x}$ surface density increases. They are silent, however, about why domains of intermediate size are more reactive or about why $\mathrm{H}_{2}$ is required for $o$-xylene isomerization. Measurements of $\mathrm{H}_{2}$ uptakes and absorption intensities in the pre-edge region of UV-visible spectra as a function of $\mathrm{WO}_{x}$ surface density suggest that reduction of $\mathrm{WO}_{x}$ domains is required to form acid sites. ${ }^{3}$ Reversible $\mathrm{H}_{2}$ chemisorption uptakes as a function of $\mathrm{WO}_{x}$ surface density at catalytic temperatures $(523 \mathrm{~K})$ parallel $o$-xylene isomerization rates (Fig. 4). Uptakes increased linearly with increasing $\mathrm{H}_{2}$ pressure, reached maximum values at $\mathrm{WO}_{x}$ surface densities of $\sim 10 \mathrm{~W} \mathrm{~nm}^{-2}$, and then decreased, as also found for catalytic rates. ${ }^{1}$ These data suggest that neutral $\mathrm{WO}_{x}$ domains chemisorb $\mathrm{H}_{2}$ to form reduced domains, such as those depicted schematically in Scheme 2, during contact with $\mathrm{H}_{2}$ at temperatures relevant to xylene isomerization catalysis. The decrease in $\mathrm{H}_{2}$ chemisorption uptakes at high $\mathrm{WO}_{x}$ surface densities corresponds to a decrease in dispersion and the formation of oxygen deficient $\mathrm{WO}_{3-x}$ species that do not reduce further or chemisorb hydrogen. ${ }^{3}$

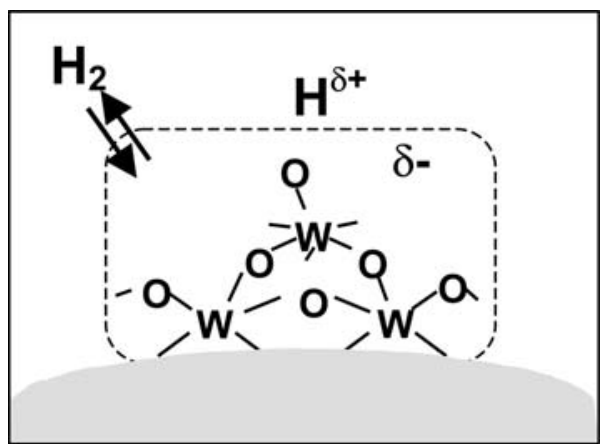

Scheme 2 The formation of bronze-like nanostructures with Brønsted acid sites via $\mathrm{H}_{2}$ chemisorption on neutral $\mathrm{WO}_{x}$ domains.

We note that $\mathrm{H}_{2}$ chemisorption leads to the reduction of $\mathrm{WO}_{x}$ domains and the parallel addition of charge-balancing protons forming the Brønsted acid sites required for $o$-xylene isomerization turnovers. This proposal is consistent with the amount of $\mathrm{H}_{2}$ chemisorbed at reaction conditions $(523 \mathrm{~K}$, $100 \mathrm{kPa} \mathrm{H}_{2}$ ), which increased in parallel as catalytic rates increased with $\mathrm{WO}_{x}$ surface density (Fig. 4).

Fig. 4 shows that $\mathrm{WO}_{x}$ domains present at surface densities below 3-4 $\mathrm{W} \mathrm{nm}^{-2}$ do not chemisorb $\mathrm{H}_{2}$ at $523 \mathrm{~K}$. They also do not catalyze $o$-xylene isomerization reactions at detectable rates. $\mathrm{H}_{2}$ chemisorption causes reduction of $\mathrm{WO}_{x}$ domains, a process favored by low LUMO energies. Low-lying LUMO levels lead, in turn, to lower edge energies in the UV-visible spectra, because HOMO levels at $\mathrm{O}$-atoms remain relatively constant with domain size. ${ }^{26}$ Thus, it appears that larger domains, with LUMO energies below those in isolated $\mathrm{WO}_{x}$ species, undergo stoichiometric reduction more readily and lead to catalysts with a larger number of Brønsted acid sites.

Reduction events can be detected as "color centers" in semiconductors, because of the placement of electrons in dorbitals, typically empty for cations present in their highest oxidation state. These electrons are involved in $\mathrm{d}-\mathrm{d}$ transitions at energies below the edge. ${ }^{2}$ For domains with several metal centers, reduction also introduces inter-valence charge transfer (IVCT) processes in the pre-edge region. $\mathrm{W}^{6+}$ species with empty d-orbitals acquire d-electrons upon reduction and show $\mathrm{d}-\mathrm{d}$ and IVCT transitions at photon energies below those required for LMCT processes.

Contact with $\mathrm{H}_{2}$ at catalytic conditions led to detectable absorption intensity in the pre-edge region because of these $\mathrm{d}-\mathrm{d}$ and IVCT transitions, consistent with reduction events. ${ }^{2}$ The extent of reduction, measured from the intensity of these pre-edge features, increased with increasing $\mathrm{WO}_{x}$ surface density. No reduction was detected at surface densities that lead to the predominant presence of monotungstate species and to undetectable $o$-xylene isomerization rates. The pre-edge features in the UV-visible spectrum during $\mathrm{H}_{2}$ treatments at higher temperatures (or at catalytic temperatures for samples with more easily reduced bulk-like $\mathrm{WO}_{3}$ clusters) may also reflect the formation of oxygen-deficient and reduced $\mathrm{WO}_{3-x}$ species formed via dehydroxylation of $\mathrm{W}-\mathrm{OH}$ groups with a concomitant loss of Brønsted acid sites. Reduced centers in $\mathrm{WO}_{3}$ clusters can also form via the stabilization of $\mathrm{H}$-atoms as bulk tungsten bronzes, which contain reduced centers but with largely 


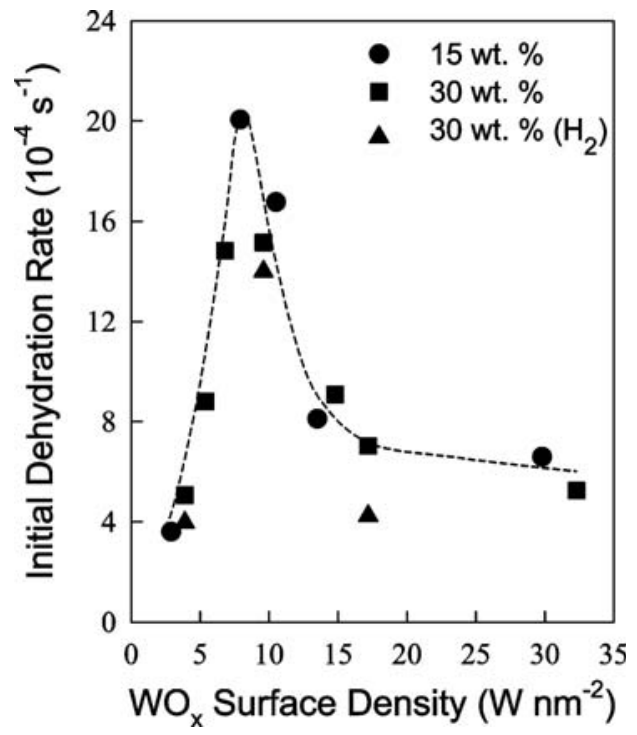

Fig. 5 Initial 2-butanol dehydration rate (per W atom) at $373 \mathrm{~K}$ as a function of $\mathrm{WO}_{x}$ surface density for two tungsten concentrations ( $\mathrm{WO}_{3}$ basis), $15 \mathrm{wt} \% \mathrm{WO}_{3}(\bullet)$ and $30 \mathrm{wt} \% \mathrm{WO}_{3}(\mathbf{\square})$, using $\mathrm{He}$ $(100.8 \mathrm{kPa})$ as the carrier. The $30 \% \mathrm{WO}_{3}$ sample is also shown with $\mathrm{H}_{2}$ $(100.8 \mathrm{kPa})$ as the carrier $(\mathbf{\Delta})$. Reprinted from J. Catal., 205, C. D. Baertsch, K. T. Komala, Y. H. Chua and E. Iglesia, Genesis of Brønsted acid sites during dehydration of 2-butanol on tungsten oxide catalysts, 44-57, Copyright 2002, with permission from Elsevier.

inaccessible hydrogen atoms. As a result, correlations between $o$ xylene isomerization rates and pre-edge intensities become inaccurate for samples containing bulk-like three-dimensional $\mathrm{WO}_{3}$ clusters. ${ }^{3}$ The substantial absence of a bulk region in twodimensional polytungstates allows protons to remain accessible at external surfaces and leads to the unique ability of these polytungstate species to catalyze reactions requiring Brønsted acid sites.

The useful properties of dispersed $\mathrm{WO}_{x}$ domains as acid catalysts and the marked effects of $\mathrm{WO}_{x}$ surface density on catalytic rates are not unique to $o$-xylene isomerization reactions. ${ }^{10}$ 2-Butanol dehydration rates also increased with $\mathrm{WO}_{x}$ surface density and then decreased as surface densities increased above $8-10 \mathrm{~W} \mathrm{~nm}{ }^{-2}$ (Fig. 5). These effects are observed, however, at lower temperatures than those required for $o$-xylene isomerization catalysis or $\mathrm{H}_{2}$ chemisorption. 2Butanol dehydration rates, in fact, did not depend on $\mathrm{H}_{2}$ pressure (0-100 kPa) (Fig. 5); yet, the dependence of rates on $\mathrm{WO}_{x}$ surface density was identical to that measured for $o$ xylene isomerization, where the effects of domain size reflect the tendency of $\mathrm{WO}_{x}$ domains to be reduced by $\mathrm{H}_{2}$ during catalysis ( $c f$. Fig. 1 and 5) so as to form the required Brønsted acid sites.

Reduced centers were detected in UV-visible spectra measured during 2-butanol dehydration catalysis, even without added $\mathrm{H}_{2}$. The intensity of pre-edge features was unaffected by the concurrent presence of $\mathrm{H}_{2}$. Fig. 6 shows the intensity of pre-edge features during 2-butanol dehydration as a function of $\mathrm{WO}_{x}$ surface density. Pre-edge intensities increased in parallel with 2-butanol dehydration rates, suggesting that species responsible for such features act as active sites or

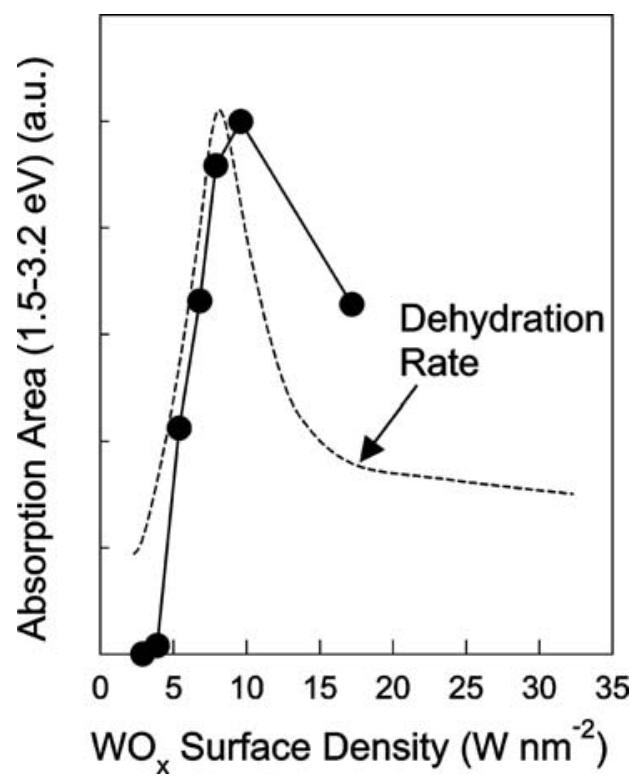

Fig. 6 Integrated UV-Vis absorption area as a function of $\mathrm{WO}_{x}$ surface density during 2-butanol dehydration catalysis at the reaction conditions for the data in Fig. 5 plotted together with a dashed curve corresponding to 2-butanol dehydration data from Fig. 5. Reprinted from J. Catal., 205, C. D. Baertsch, K. T. Komala, Y. H. Chua and E. Iglesia, Genesis of Brønsted acid sites during dehydration of 2-butanol on tungsten oxide catalysts, 44-57, Copyright 2002, with permission from Elsevier.

intermediates. ${ }^{10}$ These data show that 2-butanol itself acts as the reductant during catalysis, with the concurrent formation of trace amounts of ketones, and that it is more effective at forming reduced centers than either $o$-xylene or $\mathrm{H}_{2}$. The more reducible nature of larger $\mathrm{WO}_{x}$ domains leads to accessible reduced centers that increase and then decrease in number with increasing $\mathrm{WO}_{x}$ surface density. These reduced centers form via the stoichiometric use of 2-butanol as a sacrificial reductant, but require the continuous presence of $\mathrm{H}_{2}$ and higher temperatures when less reactive $o$-xylene species are used as reactants.

We propose that reduction of neutral $\mathrm{WO}_{x}$ domains leads to active acid sites and that 2-butanol dehydration requires such Brønsted acid sites. Both Lewis and Brønsted acid sites, however, can catalyze alkanol dehydration reactions. ${ }^{27-32}$ Measurements of Brønsted and Lewis acid site densities must be carried out during 2-butanol dehydration, because 2-butanol forms the relevant Brønsted acid sites. Acid sites were titrated during 2-butanol dehydration by 2,6-di-tertbutylpyridine, an organic base that is protonated by Brønsted acid sites, but which cannot coordinate to Lewis acid centers because of the steric bulk imposed by the tert-butyl groups. ${ }^{10,17}$ In this manner, the concentration and the involvement of Brønsted acid sites (instead of Lewis acid sites) in 2-butanol dehydration can be determined from the number of titrants adsorbed and the catalytic consequences of their adsorption.

2-Butanol dehydration rates decreased linearly as the number of adsorbed 2,6-di-tert-butylpyridine molecules increased, consistent with the involvement of Brønsted acid sites. ${ }^{10}$ The number of titrant molecules required to suppress dehydration rates increased as the $\mathrm{WO}_{x}$ surface density and the initial 2-butanol dehydration rates increased in parallel (Fig. 7). Catalytic rates 
depend more sensitively on surface densities than titrant uptakes because both Brønsted acid site densities and their reactivity are highest for intermediate surface densities (see also Fig. 9). ${ }^{33}$

The identity of the support can influence the reducibility and electronic properties of small oxide domains dispersed on their surfaces because of the intimate contact inherent in the stabilization of such small domains. Catalytic 2-butanol dehydration rates, Brønsted acid site densities, and the dynamics and extent of reduction were measured on $\mathrm{WO}_{x}$ domains supported on $\mathrm{ZrO}_{2}, \mathrm{Al}_{2} \mathrm{O}_{3}, \mathrm{SiO}_{2}$, and $\mathrm{SnO}_{2} .{ }^{33}$ These supports were chosen because their electronic properties (inferred from their band gaps) would allow different extents of electronic communication with $\mathrm{WO}_{x}$ domains. Electron delocalization onto the support would benefit from support conduction bands similar in energy to the LUMO in $\mathrm{WO}_{x}$ domains. The conduction band energy for the supports decreases, ${ }^{34}$ and the $\mathrm{WO}_{x}$-support band matching improves, in the order $\mathrm{SiO}_{2}>$ $\mathrm{Al}_{2} \mathrm{O}_{3}>\mathrm{ZrO}_{2}>\mathrm{SnO}_{2}$, as the reducibility increases and the band gap decreases for support materials.

On $\mathrm{WO}_{x}-\mathrm{Al}_{2} \mathrm{O}_{3}, 2$-butanol dehydration rates (per $\mathrm{W}$ atom) increased with increasing $\mathrm{WO}_{x}$ surface density and reached maximum values at $\mathrm{WO}_{x}$ surface densities $\left(7-10 \mathrm{~W} \mathrm{~nm} \mathrm{~nm}^{-2}\right.$ ) (Fig. 8) ${ }^{33}$ similar to those required for two-dimensional polytungstates, as also observed in $\mathrm{WO}_{x}-\mathrm{ZrO}_{2}$. UV-visible edge energies indicate that $\mathrm{WO}_{x}$ domains grow with $\mathrm{WO}_{x}$ surface density and ultimately lead to $\mathrm{WO}_{3}$ crystallites on all supports. ${ }^{33}$ The selective titration of Brønsted acid sites by stericallyhindered 2,6-di-tert-butylpyridine showed that 2-butanol dehydration reactions require Brønsted acid sites on $\mathrm{WO}_{x}$ domains for all supports. Pre-edge features appear in the UV-visible spectra of $\mathrm{WO}_{x}-\mathrm{Al}_{2} \mathrm{O}_{3}$ samples during 2-butanol hydration and their intensity increased with $\mathrm{WO}_{x}$ surface density, in parallel with measured Brønsted acid site densities and

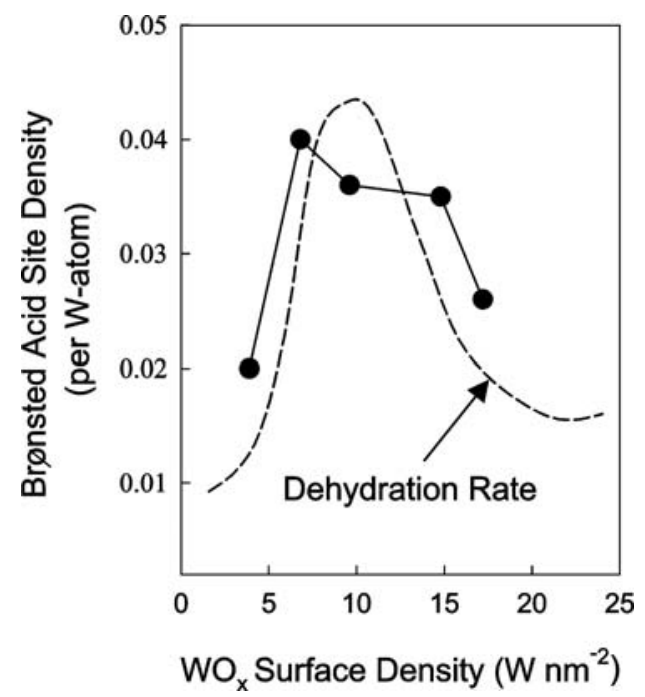

Fig. 7 Brønsted acid site densities (per $\mathrm{W}$ atom) measured for $\mathrm{WO}_{x}-\mathrm{ZrO}_{2}$ samples from 2,6-di-tert-butylpyridine titration during 2butanol dehydration catalysis at the same reaction conditions as the data in Fig. 5; 2-butanol dehydration rates from Fig. 5 are shown as a dashed curve. Reprinted from J. Catal., 205, C. D. Baertsch, K. T. Komala, Y. H. Chua and E. Iglesia, Genesis of Brønsted acid sites during dehydration of 2-butanol on tungsten oxide catalysts, 44-57, Copyright 2002, with permission from Elsevier.

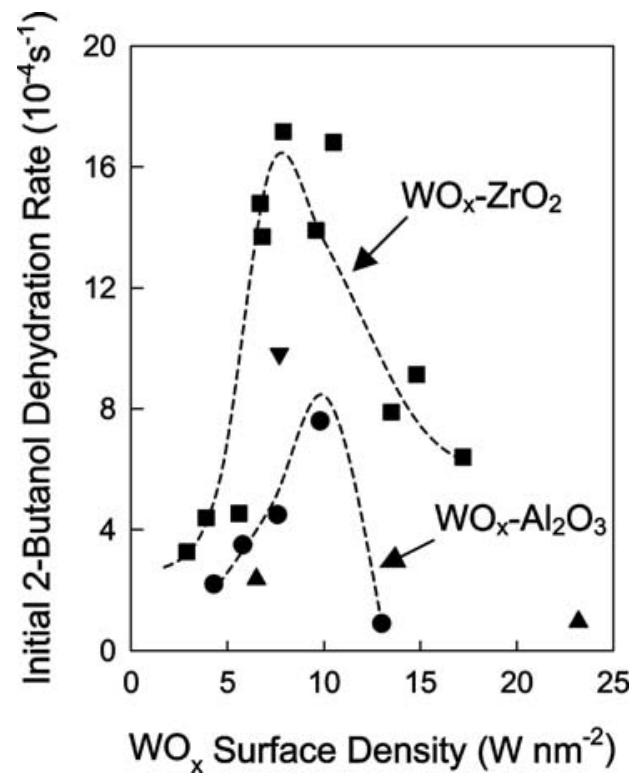

Fig. 8 Initial 2-butanol dehydration rates (per W atom) at $373 \mathrm{~K}$ as a function of $\mathrm{WO}_{x}$ surface density [0.5 $\mathrm{kPa}$ 2-butanol, $\left.100.8 \mathrm{kPa} \mathrm{He}\right]$. Catalysts shown: $\mathrm{WO}_{x}-\mathrm{Al}_{2} \mathrm{O}_{3}(\bullet), \mathrm{WO}_{x}-\mathrm{ZrO}_{2}(\boldsymbol{\square}), \mathrm{WO}_{x}-\mathrm{SiO}_{2}(\boldsymbol{\Delta})$ and $\mathrm{WO}_{x}-\mathrm{SnO}_{2}(\boldsymbol{\nabla})$. Reprinted from J. Catal., 227, J. Macht, C. D. Baertsch, M. May-Lozano, S. L. Soled, Y. Wang and E. Iglesia, Support effects on Brønsted acid site densities and alcohol dehydration turnover rates on tungsten oxide domains, 479-491, Copyright 2004, with permission from Elsevier.

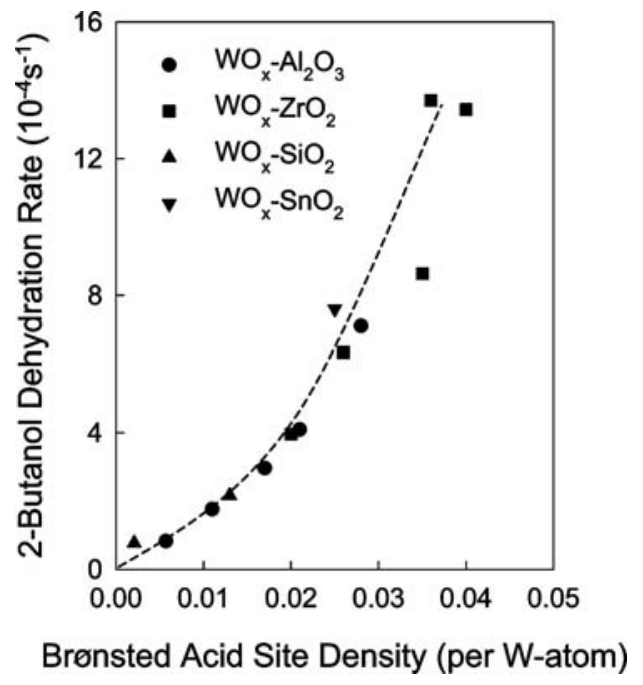

Fig. 9 Dehydration rates (per W atom) as a function of Brønsted acid site density. Initial dehydration rates were determined by 2-butanol dehydration reactions, and the dehydration rates shown are extrapolated to zero conversion and the small residual rates from on Lewis acid sites are rigorously subtracted). The error introduced by taking the residual rates without extrapolation to zero reactant conversion is assumed to be minimal, since these rates were obtained at very low conversions. Brønsted acid site densities were determined by titration with 2,6-di-tert-butylpyridine. Different catalysts are shown: $\mathrm{WO}_{x}-\mathrm{Al}_{2} \mathrm{O}_{3}(\bullet), \mathrm{WO}_{x}-\mathrm{ZrO}_{2}(\boldsymbol{\square}), \mathrm{WO}_{x}-\mathrm{SiO}_{2}(\boldsymbol{\Delta})$ and $\mathrm{WO}_{x}-\mathrm{SnO}_{2}$

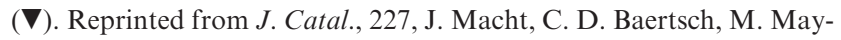
Lozano, S. L. Soled, Y. Wang and E. Iglesia, Support effects on Brønsted acid site densities and alcohol dehydration turnover rates on tungsten oxide domains, 479-491, Copyright 2004, with permission from Elsevier. 
dehydration rates (per $\mathrm{W}$ atom). ${ }^{33}$ These processes resemble those detected on $\mathrm{WO}_{x}-\mathrm{ZrO}_{2}$, indicating that temporary acid sites form via reduction of neutral $\mathrm{WO}_{x}$ domains on all supports.

Dehydration turnover rates (per Brønsted acid site) were unaffected by the identity of the support, as shown by the dehydration rate (per W atom) curve as a function of Brønsted acid density (Fig. 9). The convex character of the dehydration rate curve implies that, on all supports, the turnover rate increases as the density of Brønsted acid site increases. This reflects either an overestimation of active Brønsted acid sites at low Brønsted acid densities or more reactive acid sites at high site densities. ${ }^{33}$ For a given $\mathrm{WO}_{x}$ surface density, however, the number of reduced centers and the density of Brønsted acid sites (but not their intrinsic reactivity) were sensitive to the identity of the support (Fig. 9). Reduced centers, acting as Brønsted acid sites, were more abundant for $\mathrm{WO}_{x}$ domains supported on $\mathrm{ZrO}_{2}$ than for those supported on $\mathrm{Al}_{2} \mathrm{O}_{3}$, because of the more effective electronic isolation of $\mathrm{WO}_{x}$ on more insulating and non-reducible $\mathrm{Al}_{2} \mathrm{O}_{3}$ supports. Such electronic isolation restricts delocalization to the domains themselves and makes domains dispersed on $\mathrm{Al}_{2} \mathrm{O}_{3}$ more resistant to reduction than on $\mathrm{ZrO}_{2}$. Supports influence the ability of $\mathrm{WO}_{x}$ domains to delocalize electron density during reduction processes required to form Brønsted acid sites. Supports with smaller band gaps (e.g., $\mathrm{SnO}_{2}$ and $\mathrm{ZrO}_{2}$ ) give larger Brønsted acid site densities and more reducible $\mathrm{WO}_{x}$ domains than insulating oxides with larger band gaps (e.g., $\mathrm{SiO}_{2}$ and $\mathrm{Al}_{2} \mathrm{O}_{3}$ ). As a result, data for $\mathrm{WO}_{x}$ domains on the latter supports appear towards lower values of the abscissa in Fig. 9.

We conclude from these data that the ability of $\mathrm{WO}_{x}$ domains to form Brønsted acid sites via stoichiometric reduction processes depends on their size and dimensionality, which increase monotonically with increasing $\mathrm{WO}_{x}$ surface density. At surface densities significantly above monolayer coverages, dehydroxylation events and the formation of tungsten bronzes with inaccessible protons ultimately lead to a decrease in Brønsted acid site density (per $\mathrm{W}$ atom) as $\mathrm{WO}_{x}$ surface density increases. These processes are also influenced by the ability of supports to delocalize charge beyond the $\mathrm{WO}_{x}$ domains themselves. Reduction depends on the ability of $\mathrm{WO}_{x}$ domains to accept electron density, which depends in turn on their size and ability to communicate with supports. These properties are reflected in the energies required to induce ligand-to-metal charge transfer from $\mathrm{O}$-atoms to $\mathrm{W}$ atoms in supported $\mathrm{WO}_{x}$ domains. In some sense, the observed changes in UV-visible edge energies, which we initially meant to use as an indirect descriptor of domain size, provide instead a more direct measure of the ability of $\mathrm{WO}_{x}$ domains to undergo reduction, because such energies reflect the position of the LUMO, where additional electrons must be placed upon reduction. The position of this LUMO is of fundamental importance in both chemical reduction and in the electronic transitions measured in the UV-visible spectrum, and leads to the marked consequences for acid catalysis on these oxide domains.

\section{Acid catalysis on $\mathrm{SiO}_{2}$ supported Keggin-type polyoxometalate clusters}

Keggin-type polyoxometalate (POM) clusters $\left(\mathrm{H}_{8-n} \mathrm{X}^{n+}\right.$ $\mathrm{W}_{12} \mathrm{O}_{40}$, where $\left.\mathrm{X}=\mathrm{P}^{5+}, \mathrm{Si}^{4+}, \mathrm{Al}^{3+}, \mathrm{Co}^{2+}\right)$ are composed of neutral $\mathrm{W}_{12} \mathrm{O}_{36}$ shells encapsulating an $\mathrm{X}^{n+} \mathrm{O}_{4}{ }^{-(8-n)}$ anion surrounded by $(8-n)$ charge-balancing protons. These clusters have, except for a central atom $\mathrm{X}$, the same composition $\left(\mathrm{H}_{x} \mathrm{WO}_{y}\right)$ and distorted $\mathrm{WO}_{6}$ octahedral building blocks as supported $\mathrm{WO}_{x}$ domains. These materials have permanent Brønsted acid sites because of the charge imbalance imposed by the encapsulated $\mathrm{X}^{n+} \mathrm{O}_{4}{ }^{-(8-n)}$ anion. Stoichiometric reduction processes that form $\mathrm{H}^{\delta+}\left(\mathrm{WO}_{3}\right)_{n}{ }^{\delta-}$ species are not required for Brønsted acidity in these samples. In contrast with the disordered and poorly defined $\mathrm{WO}_{x}$ domains discussed above, the well-defined structure, composition, and size of $\mathrm{H}_{8-n} \mathrm{X}^{n+} \mathrm{W}_{12} \mathrm{O}_{40}$ POM clusters allow reliable assessments of composition-function relations using experiments and theory.

2-Butanol dehydration rate constants reflect the enthalpy and entropy of the carbenium-ion transition state relative to those for hydrogen-bonded adsorbed 2-butanol molecules involved in kinetically-relevant elimination steps. These rate constants were measured from rate data using an equation derived from elementary steps that include adsorption of 2butanol via $\mathrm{H}$-bonding, elimination of water via $\mathrm{E} 1$ pathways, desorption of the bound butoxides, and the formation of unreactive butanol dimers. ${ }^{35}$ Elimination rate constants decreased with increasing deprotonation enthalpy (DPE) $\left(\Delta \mathrm{H}_{\mathrm{rxn}}\right.$ : $\mathrm{AH} \rightarrow \mathrm{A}^{-}+\mathrm{H}^{+} ; \mathrm{AH}$ is the neutral cluster; $\mathrm{A}^{-}$is the deprotonated POM), a rigorous measure of acid strength (Fig. 10) estimated from density functional calculations. ${ }^{35}$ DPE values for $\mathrm{H}_{8-n} \mathrm{X}^{n+} \mathrm{W}_{12} \mathrm{O}_{40}$ POM clusters increased $\left(1087 \mathrm{~kJ} \mathrm{~mol}^{-1}\left(\mathrm{H}_{3} \mathrm{PW}_{12} \mathrm{O}_{40}\right), 1143 \mathrm{~kJ} \mathrm{~mol}^{-1}\left(\mathrm{H}_{6} \mathrm{Co} \mathrm{W}_{12} \mathrm{O}_{40}\right)\right.$ as the valence of the central atom $\mathrm{X}$ decreased and the number of protons concurrently increased, indicative of a concomitant decrease in acid strength.

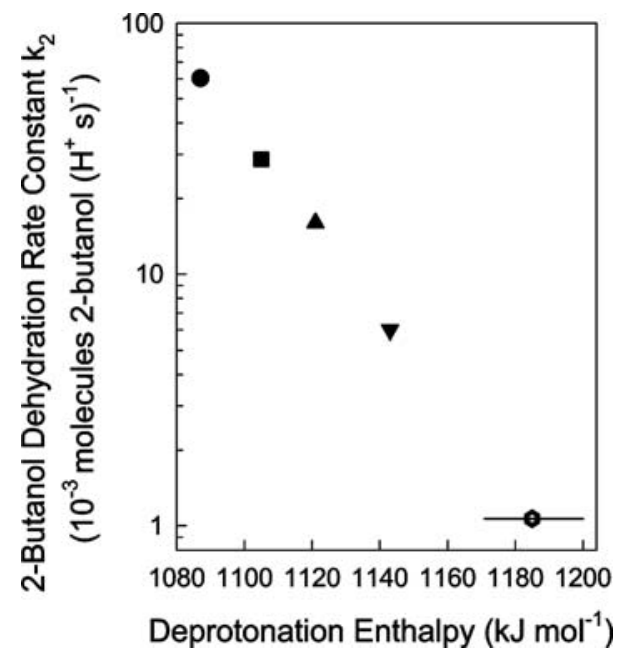

Fig. 10 2-Butanol decomposition rate constant $\mathrm{k}_{2}$ at $343 \mathrm{~K}$ as a function of deprotonation enthalpy, defined as $\Delta \mathrm{H}_{\mathrm{rxn}}$ of $\mathrm{HA} \rightarrow \mathrm{A}^{-}+$ $\mathrm{H}^{+}$(HA is the acid, an $\mathrm{A}^{-}$is the conjugate base) and calculated by DFT. $\left(\mathrm{H}_{3} \mathrm{PW}_{12} \mathrm{O}_{40}-\mathrm{SiO}_{2}(\bigcirc), \mathrm{H}_{4} \mathrm{SiW}_{12} \mathrm{O}_{40}-\mathrm{SiO}_{2}(\square), \mathrm{H}_{5} \mathrm{AlW}_{12} \mathrm{O}_{40^{-}}\right.$ $\mathrm{SiO}_{2}(\boldsymbol{\Delta})$ and $\mathrm{H}_{6} \mathrm{CoW}_{12} \mathrm{O}_{40}-\mathrm{SiO}_{2}(\boldsymbol{\nabla})\left(0.04\right.$ POM nm $\left.{ }^{-2}\right)$ and H-BEA (). J. Macht, M. J. Janik, M. Neurock and E. Iglesia, Catalytic Consequences of Composition in Polyoxometalate Clusters with Keggin Structure, Angew. Chem., Int. Ed., 2007, 46, 7864-7868. Copyright Wiley-VCH Verlag GmbH \& Co. KGaA. Reproduced with permission. 
Keggin-type POM clusters are stronger Brønsted acids than zeolites in their proton form (DPE: $1171 \mathrm{~kJ} \mathrm{~mol}^{-1}$ (zeolite $\left.\mathrm{Y})-1200 \mathrm{~kJ} \mathrm{~mol}^{-1}(\mathrm{ZSM}-5)\right)^{36}$ and $\mathrm{H}_{2} \mathrm{SO}_{4}\left(1300 \mathrm{~kJ} \mathrm{~mol}^{-1}\right)$. Their DPE values also span a wider range $\left(56 \mathrm{~kJ} \mathrm{~mol}^{-1}\right)^{35}$ than for zeolite structures (Y, CHA, MOR, and MFI$\left.29 \mathrm{~kJ} \mathrm{~mol}^{-1}\right){ }^{36}$ The higher DPE of Brønsted acid sites in $\mathrm{H}-$ BEA led to lower values of the rate constant of the elimination step (Fig. 10) than on POM clusters. The observed increase in DPE with decreasing valence of the central atom $\mathrm{X}_{\text {in }} \mathrm{H}_{8-n} \mathrm{X}^{n+}$ $\mathrm{W}_{12} \mathrm{O}_{40}$ Keggin clusters also led to a concomitant increase in elimination activation barriers calculated by DFT methods, consistent with the observed decrease in experimental rate constants for elimination steps. The monotonic decrease in 2butanol dehydration rate constants with DPE (Fig. 10) suggests that elimination rate constants can be used to assess acid strength and DPE values for many Brønsted acid catalysts whose ill-defined structure prevents rigorous theoretical DPE or acid strength estimates, such as the dispersed $\mathrm{H}^{\delta+}$ $\left(\mathrm{WO}_{3}\right)_{n}{ }^{\delta-}$ species discussed in the previous section. In such cases, measured values, rigorously normalized by the number of protons accessible during reaction can be used to estimate DPE from the value in the abscissa of Fig. 10 corresponding to the measured rate constants.

Deprotonation of Brønsted acids requires the redistribution of electron density from the $\mathrm{A}-\mathrm{H}$ bond in the parent acid cluster throughout the entire anionic cluster $\mathrm{A}^{-}$. In contrast with reduction processes, deprotonation events maintain a constant number of electrons within the cluster. DPE values decrease (and the acids become stronger) as the two electrons involved in $\mathrm{A}-\mathrm{H}$ bonds are redistributed over larger anions. Deprotonation of $\mathrm{H}_{8-n} \mathrm{X}^{n+} \mathrm{W}_{12} \mathrm{O}_{40}$ increases the electron density evenly over the entire $\left(\mathrm{H}_{7-n} \mathrm{X}^{n+} \mathrm{W}_{12} \mathrm{O}_{40}\right)^{-}$anion. ${ }^{37}$ In contrast, charge is highly localized on inorganic insulators, such as the silicate framework in zeolites, and deprotonation enthalpies are therefore higher and Brønsted acid sites weaker in zeolites than in POM clusters. The estimation of DPE values from electronic structure methods is straightforward for well-defined clusters, but their interpretation in terms of the electronic structure, electron distribution, and composition of the acid is more challenging.

For $\mathrm{H}_{8-n} \mathrm{Y}^{n+} \mathrm{O}_{4}\left(\mathrm{Y}=\mathrm{Cl}^{7+}, \mathrm{S}^{6+}, \mathrm{P}^{5+}\right.$ and $\left.\mathrm{Si}^{4+}\right)$ and $\mathrm{H}_{8-n} \mathrm{X}^{n+} \mathrm{W}_{12} \mathrm{O}_{40}\left(\mathrm{X}=\mathrm{P}^{5+}, \mathrm{Si}^{4+}, \mathrm{Al}^{3+}, \mathrm{Co}^{2+}\right)$ acids, we find that DPE values decrease as the negative charge in $\mathrm{O}$-atoms decreases concurrently with an increase in the valence of $\mathrm{X}$ or $\mathrm{Y}$ in $\mathrm{H}_{8-n} \mathrm{X}^{n+} \mathrm{W}_{12} \mathrm{O}_{40}$ and $\mathrm{H}_{8-n} \mathrm{Y}^{n+} \mathrm{O}_{4}$, respectively, and a decrease in the number of charge-balancing protons. ${ }^{38} \mathrm{DPE}$ values also decrease as the size of the anion increases, because the additional electron is delocalized over larger domains. DPE values are smaller by $304 \mathrm{~kJ} \mathrm{~mol}^{-1}$ and $376 \mathrm{~kJ} \mathrm{~mol}^{-1}$ and the differences in DPE values decrease from $90 \mathrm{~kJ} \mathrm{~mol}^{-1}$ to $18 \mathrm{~kJ} \mathrm{~mol}^{-1}$ for $\mathrm{H}_{3} \mathrm{PW}_{12} \mathrm{O}_{40}$ and $\mathrm{H}_{4} \mathrm{SiW}_{12} \mathrm{O}_{40}$, respectively, compared to their respective non-encapsulated analogs$\mathrm{H}_{3} \mathrm{PO}_{4}$ and $\mathrm{H}_{4} \mathrm{SiO}_{4}$. These differences clearly illustrate the critical role of electron delocalization, which occurs in POM clusters over a much larger $\mathrm{W}_{12} \mathrm{O}_{36}$ shell ${ }^{38}$ than for the bare acids, in decreasing DPE values and increasing acid strength.

The ill-defined structure of dispersed $\mathrm{WO}_{x}$ catalysts precludes rigorous estimates of their DPE values as they reduce and form acidic $\mathrm{O}-\mathrm{H}$ species. Rate constants (per accessible proton) for 2-butanol dehydration on $\mathrm{WO}_{x}-\mathrm{ZrO}_{2}(1.35 \times$ $\left.10^{-3}\left(\mathrm{~s} \mathrm{H}^{+}\right)^{-1.10} ;^{6} 6.8 \mathrm{~W} \mathrm{~nm}^{-2}\right)$ are similar to those on H-BEA $\left(1.1 \times 10^{-3}\left(\mathrm{~s} \mathrm{H}^{+}\right)^{-1}\right)^{35}$ at $343 \mathrm{~K}$, but much smaller than on $\mathrm{H}_{3} \mathrm{PW}_{12} \mathrm{O}_{40}\left(60 \times 10^{-3}\left(\mathrm{~s} \mathrm{H}^{+}\right)^{-1}\right){ }^{35}$ We conclude that $\mathrm{H}^{\delta+}\left(\mathrm{WO}_{3}\right)_{n}{ }^{\delta-}$ species on $\mathrm{WO}_{x}-\mathrm{ZrO}_{2}$ are similar in acid strength and DPE to zeolites (DPE $\sim 1200 \mathrm{~kJ} \mathrm{~mol}^{-1}$ ) and much weaker acids than Keggin POM clusters.

Marked effects of DPE values have also been observed for bifunctional alkane isomerization, carried out on physical mixtures of $\mathrm{Pt} / \mathrm{Al}_{2} \mathrm{O}_{3}$ and the corresponding acids. These mixtures ensure that the metal dehydrogenation function establishes alkane-alkene quasi-equilibrium and that the isomerization step on the acid is the sole kinetically-relevant step. This kinetically-relevant isomerization step involves a protonated cyclopropyl species in the transition state. ${ }^{39}$ The isomerization rate constant decreased with increasing DPE in a manner reminiscent of that observed for 2-butanol elimination rate constants. ${ }^{40}$ Isomerization rate constants decreased as the valence of the central atom $\mathrm{X}$ on $\mathrm{H}_{8-n} \mathrm{X}^{n+} \mathrm{W}_{12} \mathrm{O}_{40} \mathrm{POM}$ clusters decreased and DPE values concurrently increased. As in the case of 2-butanol dehydration, isomerization rate constants on $\mathrm{WO}_{x}-\mathrm{ZrO}_{2}$ and $\mathrm{H}$-BEA were similar to each other, but much smaller than on any $\mathrm{H}_{8-n} \mathrm{X}^{n+} \mathrm{W}_{12} \mathrm{O}_{40} \mathrm{POM}$ clusters. Thus, the ranking of acid strength based on the earlier studies of 2-butanol dehydration remains rigorously applicable to reactions of unrelated molecules. These reactions are connected only by the common requirement for carbocationic transition states in their respective kinetically-relevant steps.

\section{Oxidation catalysis on supported transition metal oxide domains}

We consider next the effects of cluster size, composition, and support, which were discussed earlier for acid catalysis, for the case of oxidation pathways. Turnover rates for such reactions should depend sensitively on the ability of oxide domains to undergo reduction-oxidation cycles, which must occur during each catalytic turnover. In contrast with redox cycles, turnovers in acid catalysis do not lead to an increase in the number of electrons in the anionic conjugate base during protonation events. In dispersed $\mathrm{WO}_{x}$ clusters, stoichiometric reduction events that form acidic $\mathrm{H}^{\delta+}\left(\mathrm{WO}_{3}\right)_{n}{ }^{\delta-}$ species are required only to form Brønsted acid sites, but electron transfer does not occur in protonation-deprotonation steps. Oxidation turnovers, in contrast, require the formal reduction of metal centers in oxide clusters and an increase in the number of electrons that must be stabilized within such clusters. Most oxidation reactions that occur via Mars-van Krevelen redox cycles are limited by the reduction step within catalytic sequences, suggesting that turnover rates should increase as clusters become increasingly able to stabilize additional electrons, which would lead to more stable activated complexes for such reduction steps.

The effects of oxide domain size on reducibility, which reflect, in turn, concomitant changes in the LUMO energies of the oxide domains, are evident in oxidative dehydrogenation of alkanes $^{4,5,11,12}$ and dimethylether ${ }^{41,42}$ on $\mathrm{Mo}, \mathrm{V}, \mathrm{Nb}$, and $\mathrm{W}$ oxides, and in methanol oxidation on dispersed $\mathrm{RuO}_{x}{ }^{43}$ and $\mathrm{PdO}_{x}{ }^{44}$ domains. We choose here oxidative alkane 


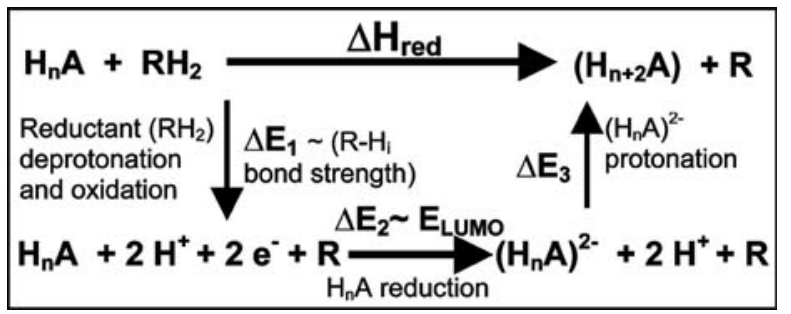

Scheme 3 Thermochemical cycle for the formation of reduced centers.

dehydrogenation catalysis to illustrate the marked effects of surface density and domain size on the electronic properties and catalytic oxidation reactivity of dispersed transition metal oxides. These examples illustrate the fundamental effect of size on the energies of ligand-to-metal charge transfer processes and on the ability of oxide domains to stabilize additional electron density during stoichiometric reduction and redox cycles.

Oxidative dehydrogenation of alkanes $(\mathrm{ODH})$ involves primary and secondary reactions, the rates of which can be measured from the effects of residence time on formation rates of alkenes and $\mathrm{CO}_{x}\left(\mathrm{CO}\right.$ and $\left.\mathrm{CO}_{2}\right){ }^{11}$ Catalytic turnovers for oxidative dehydrogenation of $\mathrm{MoO}_{x}$ and $\mathrm{VO}_{x}$ proceed via reduction-oxidation cycles. ${ }^{45-48}$ These cycles involve the removal and replacement of lattice oxygen atoms via pathways first proposed by Mars and van Krevelen. ${ }^{49}$ Reaction rates are limited by the reduction step, which involves the activation of the weakest $\mathrm{C}-\mathrm{H}$ bond in alkanes on a pair of lattice oxygen atoms at the surface of reducible oxide domains. ${ }^{50}$ This catalytic sequence, depicted in Scheme 4, requires transition states that introduce significant electron density into oxide domains during $\mathrm{C}-\mathrm{H}$ bond activation. Thus, the ability to accept electron density, which depends on the position of the LUMO $\left(\Delta \mathrm{E}_{2}\right.$; Scheme 3) is likely to lead to significant catalytic consequences.

These effects of oxide surface density and domain size on catalytic function are illustrated first for the specific case of $\mathrm{MoO}_{x}$ structures supported on $\mathrm{Al}_{2} \mathrm{O}_{3}$, but the general findings and conclusions remain valid for other supports and also for $\mathrm{VO}_{x}$ and $\mathrm{WO}_{x}$ domains. ${ }^{4}$ UV-visible spectra show the

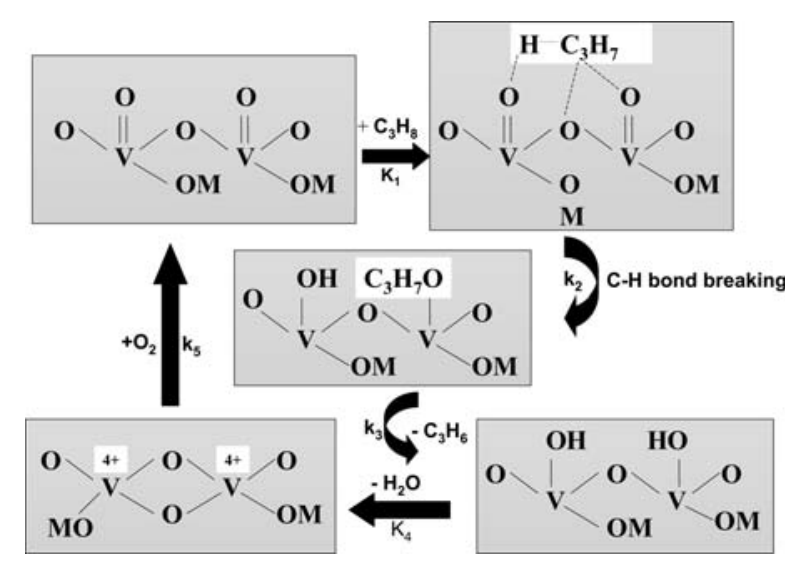

Scheme 4 Catalytic sequence for oxidative dehydrogenation of propane on oxides. Reprinted from J. Catal., 209, K. Chen, A. T. Bell and E. Iglesia, The relationship between the electronic and redox properties of dispersed metal oxides and their turnover rates in oxidative dehydrogenation reactions, 35-42, Copyright 2002, with permission from Elsevier.

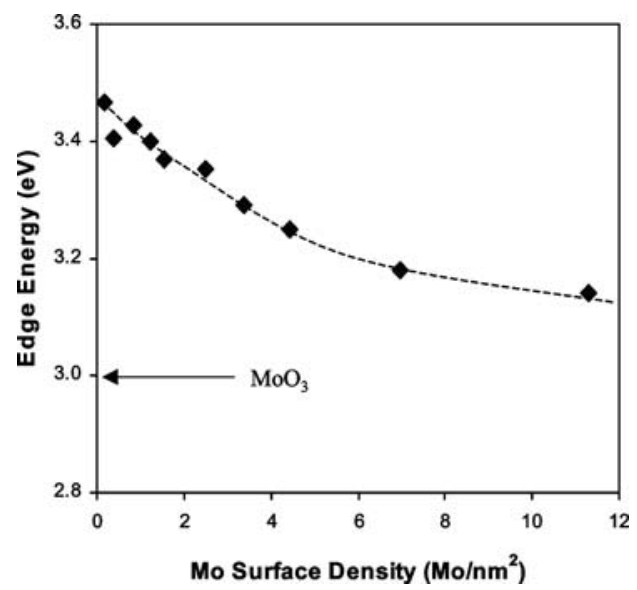

Fig. 11 Dependence of the UV-visible absorption edge energy on the Mo surface density of $\mathrm{MoO}_{x}-\mathrm{Al}_{2} \mathrm{O}_{3}$ catalysts under ambient conditions. Reprinted from J. Catal., 198, K. Chen, S. Xie, A. T. Bell and E. Iglesia, Structure and properties of oxidative dehydrogenation catalysts based on $\mathrm{MoO}_{3} / \mathrm{Al}_{2} \mathrm{O}_{3}, 232-242$, Copyright 2001, with permission from Elsevier.

expected decrease in absorption energy with increasing $\mathrm{MoO}_{x}$ surface density (Fig. 11). Raman and X-ray absorption spectra detect the concurrent evolution from isolated monomolybdate species, to polymolybdates, and ultimately to crystalline $\mathrm{MoO}_{3}$ structures, ${ }^{4}$ as $\mathrm{MoO}_{x}$ surface density increases. Thus, as in the case of $\mathrm{WO}_{x}$ domains discussed earlier, $\mathrm{MoO}_{x}$ domains increase monotonically in size and dimensionality with increasing surface density and the HOMO-LUMO gap concurrently decreases.

The catalytic consequences of this evolution in size, structure, and electronic properties are shown in Fig. 12, in which oxidative dehydrogenation rates (per Mo atom) are shown for propane reactants as a function of Mo surface density for domains dispersed on $\mathrm{Al}_{2} \mathrm{O}_{3}$. The concurrent changes observed in absorption edge energies and in the stabilization of the transition state for $\mathrm{C}-\mathrm{H}$ bond cleavage and $\mathrm{O}-\mathrm{H}$ and $\mathrm{C}-\mathrm{O}$ bond formation reflect the increased ability of larger domains

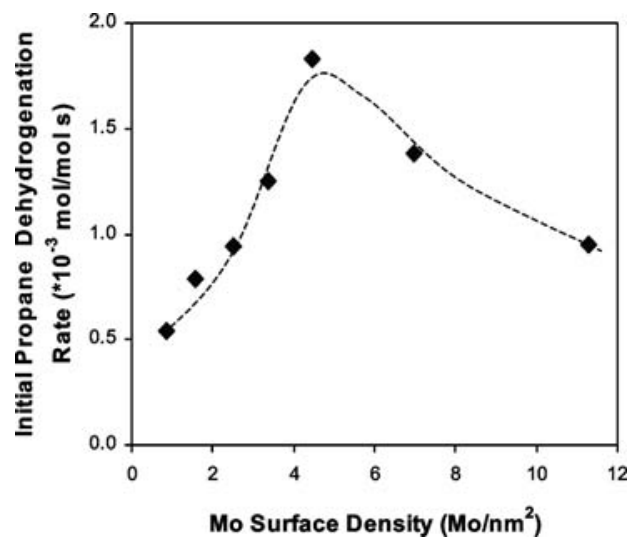

Fig. 12 Effects of Mo surface density on initial propene formation rates (per Mo-atom) on $\mathrm{MoO}_{x}-\mathrm{Al}_{2} \mathrm{O}_{3}\left(703 \mathrm{~K}, 14 \mathrm{kPa} \mathrm{C} \mathrm{H}_{8}, 1.7 \mathrm{kPa}\right.$ $\mathrm{O}_{2}$ ). Reprinted from J. Catal., 198, K. Chen, S. Xie, A. T. Bell and E. Iglesia, Structure and properties of oxidative dehydrogenation catalysts based on $\mathrm{MoO}_{3} / \mathrm{Al}_{2} \mathrm{O}_{3}, 232-242$, Copyright 2001, with permission from Elsevier. 
to accept electrons, consistent with their lower lying LUMO states and higher electron affinity. These trends are also consistent with the linear free energy relationships between reaction enthalpies and activation energies commonly observed in oxidation catalysis. For a given reactant $\left(\Delta \mathrm{E}_{1}\right.$, $\mathrm{X}-\mathrm{H}$ bond dissociation energy and $\mathrm{H}$ ionization energy, endothermic) and cluster (with protonation enthalpy $\Delta \mathrm{E}_{3}$, exothermic), a lower lying LUMO $\left(\Delta \mathrm{E}_{2}\right)$ leads to a more exothermic $\mathrm{H}$ abstraction reaction (Scheme 3) $\left(\Delta \mathrm{H}_{\mathrm{C}-\mathrm{H} \text {,abstr }}\right.$ $\left.=\Delta \mathrm{E}_{1}+\Delta \mathrm{E}_{2}+\Delta \mathrm{E}_{3}\right)$ and activation barrier $\left(\mathrm{E}_{\mathrm{act}, \mathrm{C}-\mathrm{H}, \text { abst }}\right)$ assuming an Evans-Polyani correlation of $\mathrm{E}_{\mathrm{act}, \mathrm{C}-\mathrm{H} \text {,abst }}$ and $\Delta \mathrm{H}_{\mathrm{C}-\mathrm{H} \text {,abstr }}$ according to $\mathrm{E}_{\text {act, } \mathrm{C}-\mathrm{H} \text {,abst }}=\mathrm{E}_{0}+\alpha \Delta \mathrm{H}_{\mathrm{C}-\mathrm{H} \text {,abstr }}$, where $\mathrm{E}_{0}$ and $\alpha$ are constants.

Propane oxidative dehydrogenation rates (per Mo-atom) increased with increasing surface density and decreasing edge energy, as the latter approaches values typical of saturated polymolybdate monolayers. These trends indicate that the reactivity of $\mathrm{MoO}_{x}$ surfaces increases as larger domains become increasingly able to accept electron density and to stabilize transition states required in rate-determining reduction steps relative to smaller domains with higher-lying LUMO states. Ultimately, higher surface densities lead to the formation of crystalline $\mathrm{MoO}_{x}$ with inaccessible Mo centers, which renders the use of the total number of Mo atoms inappropriate as a measure of the number of active sites. As a result, turnover rates reported on the basis of Mo atoms inevitably and ultimately decrease with increasing $\mathrm{MoO}_{x}$ surface densities (Fig. 12) as a result of the prevalence of inaccessible Mo-oxo species

These catalytic trends resemble those reported previously for oxidative dehydrogenation of propane ${ }^{46}$ and ethane ${ }^{47}$ on $\mathrm{VO}_{x}$ domains and for reactions of propane on $\mathrm{MoO}_{x}$ domains dispersed on other supports. ${ }^{45}$ Similar trends have also been observed for oxidative dehydrogenation of oxygenates on $\mathrm{VO}_{x}$ and $\mathrm{MoO}_{x}$ domains ${ }^{41,42}$ and on more reducible $\mathrm{RuO}_{x}$ domains. ${ }^{43}$ The observed effects of domain size on catalysis parallel similar effects on the dynamics of their incipient stoichiometric reduction in $\mathrm{H}_{2}$, a process that leads to the formation of isolated vacancies and which resembles the elementary steps involved in the reduction part of catalytic dehydrogenation cycles. ${ }^{45}$ Stoichiometric reduction rates increased with increasing $\mathrm{MoO}_{x}$ and $\mathrm{VO}_{x}$ surface densities, consistent with a concurrent decrease in their LUMO energies.

We consider next two questions brought forth by our observations and by our hypotheses to account for them. The first matter concerns whether a fundamental relation between LUMO levels and chemical reduction tendencies extends more broadly and beyond specific active oxides and supports. The second one addresses the demonstration that larger domains are indeed more reducible than smaller domains, and thus more reduced during oxidative dehydrogenation catalysis. Both questions are addressed by UV-visible spectroscopy, used here to measure the electronic properties and the extent of reduction of oxide domains during treatment and during oxidative dehydrogenation catalysis. Turnover rates on $\mathrm{Mo}, \mathrm{V}, \mathrm{Nb}$, and $\mathrm{W}$ oxides dispersed on various supports were measured as a function of their ligand-to-metal charge transfer energies to address the first point. The first reported measurements of the number of reduced active

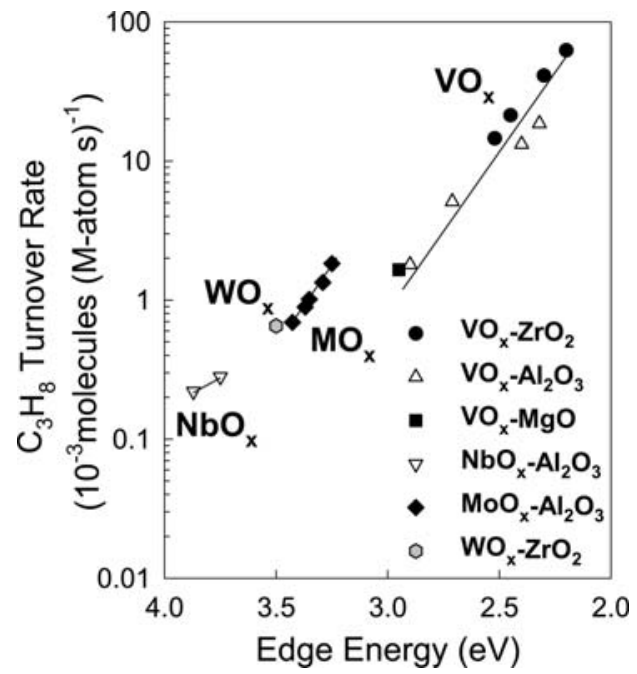

Fig. 13 Dependence of propane turnover rate $\left(703 \mathrm{~K}, 14 \mathrm{kPa} \mathrm{C}_{3} \mathrm{H}_{8}\right.$, $1.7 \mathrm{kPa} \mathrm{O}_{2}$, balance $\mathrm{He}$ ) on the UV-visible absorption edge energy for $\mathrm{MO}_{x}$ catalysts. Reprinted from J. Catal., 209, K. Chen, A. T. Bell and E. Iglesia, The relationship between the electronic and redox properties of dispersed metal oxides and their turnover rates in oxidative dehydrogenation reactions, 35-42, Copyright 2002, with permission from Elsevier.

centers during oxidative dehydrogenation catalysis were used to establish the role of reducibility during oxidation catalysis and the increasing prevalence of reduced centers as turnover rates increased with the surface density and domain size of the active oxides.

The mechanistic connections between oxidative dehydrogenation rates and the LMCT absorption edge in the electronic spectra of dispersed oxides are evident from the data shown in Fig. 13. Catalytic turnover rates on $\mathrm{VO}_{x}, \mathrm{MoO}_{x}$, $\mathrm{WO}_{x}$, and $\mathrm{NbO}_{\mathrm{x}}$ domains dispersed predominantly as monomers or two-dimensional oligomers on various supports $\left(\mathrm{Al}_{2} \mathrm{O}_{3}, \mathrm{ZrO}_{2}, \mathrm{MgO}\right)$ are shown as a function of their corresponding LMCT energies. For all active oxides, ODH turnover rates (per active metal atom) increased monotonically as LMCT energies decreased. The exponential dependence evident from the data in Fig. 13 suggests a relation between the energy required for these electronic transitions and the activation energies for kinetically-relevant steps, the activation of methylene $\mathrm{C}-\mathrm{H}$ bonds in propane reactants using lattice oxygens for this reaction. This correlation includes not only $\mathrm{MoO}_{x}$ domains on $\mathrm{Al}_{2} \mathrm{O}_{3}$ (depicted in Fig. 11 and 12) but also the other active oxides on various supports. These trends reflect the role of LUMO energies in determining the ability of oxide domains to accept electrons during reduction events that limit alkane dehydrogenation rates.

These results indicate that the stability of activated complexes in $\mathrm{C}-\mathrm{H}$ bond dissociation steps depends sensitively on the ability of oxide domains to accept electrons during $\mathrm{C}-\mathrm{H}$ bond activation. The UV-visible absorption edge energy decreases as the energy level of the LUMO decreases and as the electron affinity of the cluster (Scheme 3, $\Delta \mathrm{E}_{2}$ ) increases. These effects influence, in turn, the energies of intermediates and transition states that require electron transfer to the cluster. They lead to the exponential dependence of propane ODH 
turnover rates on LMCT absorption edge energies evident from Fig. 13. The identity of the metal has the strongest impact on both LMCT absorption edge energy and propane ODH turnover rates. More reducible supports and higher surface densities lead to higher propane ODH turnover rates for a given element and to lower edge energies and lower-lying LUMO states, which stabilize both the products and the transition state in $\mathrm{C}-\mathrm{H}$ bond activation steps (Scheme 3 and 4). $\mathrm{MoO}_{x}$ and $\mathrm{VO}_{x}$ domains can be made similar in reactivity, in spite of their different chemical identities, by dispersing the latter as smaller domains or onto less reducible supports than the former. Thus, we conclude that quantum confinement effects, imposed by the size and electronic isolation of oxide domains, can be used to design materials with electronic properties and catalytic functions controlled by properties other than chemical composition.

The detection and quantification of reduced centers during oxidation catalysis is a challenging task made possible by recent studies that exploit the sensitivity of pre-edge features to changes in orbital occupancy caused by reduction. The extent of reduction of active centers was determined in $\mathrm{VO}_{x}-\mathrm{Al}_{2} \mathrm{O}_{3}$ samples with a range of $\mathrm{VO}_{x}$ surface densities from the intensity of pre-edge $\mathrm{d}$ - $\mathrm{d}$ electronic transitions during steady-state oxidative dehydrogenation of propane. ${ }^{50}$ Pre-edge intensities were related to local electron density by using the stoichiometric reduction of $\mathrm{VO}_{x}$ by $\mathrm{H}_{2}$ and counting of reduced centers by subsequent re-oxidation of the vacancies formed with $\mathrm{O}_{2}$.

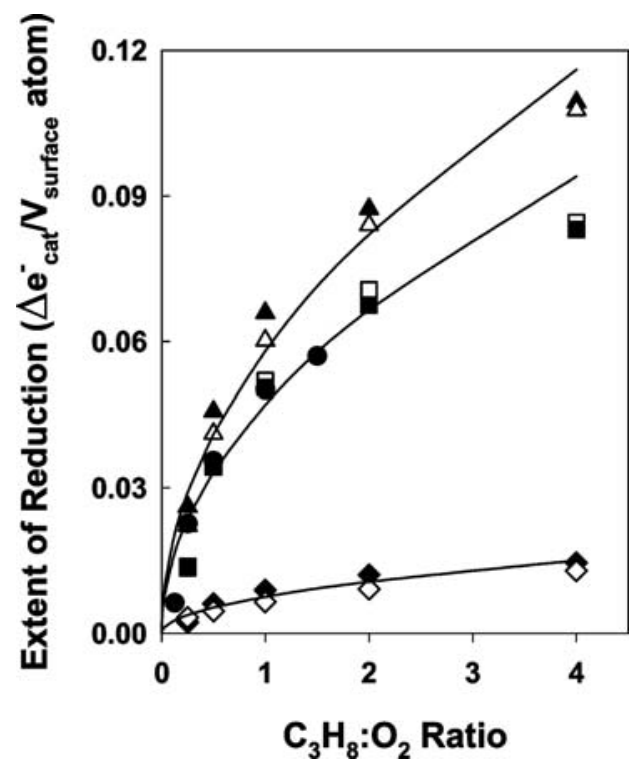

Fig. 14 Dependence of the extent of reduction per surface $\mathrm{V}$-atom on $\mathrm{C}_{3} \mathrm{H}_{8}: \mathrm{O}_{2}$ ratios for $\mathrm{VO}_{x}-\mathrm{Al}_{2} \mathrm{O}_{3}$ during propane ODH (filled symbols: $\mathrm{C}_{3} \mathrm{H}_{8}$ dependence (1.0-16 $\mathrm{kPa} \mathrm{C} \mathrm{C}_{3} \mathrm{H}_{8}, 4.0 \mathrm{kPa} \mathrm{O}$, balance $\left.\mathrm{Ar}, 603 \mathrm{~K}\right)$; open symbols: $\mathrm{O}_{2}$ dependence $\left(4.0 \mathrm{kPa} \mathrm{C}_{3} \mathrm{H}_{8}, 1.0-16 \mathrm{kPa} \mathrm{O}\right.$, balance Ar, $603 \mathrm{~K}$ ); diamonds: $3.5 \mathrm{wt} \% \mathrm{~V}_{2} \mathrm{O}_{5}-\mathrm{Al}_{2} \mathrm{O}_{3}\left(2.3 \mathrm{~V} \mathrm{~nm}^{-2}\right)$; squares: $10 \mathrm{wt} \% \mathrm{~V}_{2} \mathrm{O}_{5}-\mathrm{Al}_{2} \mathrm{O}_{3}\left(8.0 \mathrm{~V} \mathrm{~nm}{ }^{-2}\right)$; triangles: $30 \mathrm{wt} \% \mathrm{~V}_{2} \mathrm{O}_{5}-\mathrm{Al}_{2} \mathrm{O}_{3}$ $\left(34 \mathrm{~V} \mathrm{~nm}{ }^{-2}\right)$; filled circles are $\mathrm{C}_{3} \mathrm{H}_{8}$ dependence $\left(8.0 \mathrm{kPa} \mathrm{O}_{2}\right.$, 1.0-12 $\mathrm{kPa} \mathrm{C}_{3} \mathrm{H}_{8}$, balance $\mathrm{Ar}, 603 \mathrm{~K}$ ) for $10 \mathrm{wt} \% \mathrm{~V}_{2} \mathrm{O}_{5}-\mathrm{Al}_{2} \mathrm{O}_{3}$ $\left.\left(8.0 \mathrm{~V} \mathrm{~nm}^{-2}\right)\right]$. Reproduced with permission from J. Phys. Chem. B, 2004, 108, 2345-2353. Copyright 2004 American Chemical Society.
Fig. 14 shows the number of electrons introduced per $\mathrm{V}$ during catalytic reactions as a function of the reductant/oxidant ratio in reactants on $\mathrm{VO}_{x}-\mathrm{Al}_{2} \mathrm{O}_{3}$ samples with three different surface densities. The extent of reduction for all samples $\left(0.062-0.30 \mathrm{e}^{-} / \mathrm{V}\right)$ was much smaller than required for stoichiometric reduction of $\mathrm{V}^{5+}$ to $\mathrm{V}^{3+}$ or $\mathrm{V}^{4+}$ and increased with increasing reductant/oxidant ratio, as required by mechanistic considerations based on the prevalent redox cycles and the kinetic relevance of $\mathrm{C}-\mathrm{H}$ bond activation steps. ${ }^{50}$ The extent of reduction also increased with increasing $\mathrm{VO}_{x}$ surface density, consistent with the more reducible nature and higher catalytic reactivity of larger $\mathrm{VO}_{x}$ domains and with the kinetic relevance of the $\mathrm{C}-\mathrm{H}$ bond activation step, which requires the formal reduction of $\mathrm{V}^{5+}$ centers. This relation between the extent of reduction during catalysis and the propene formation rates confirms the redox nature of catalytic cycles and the exclusive kinetic relevance of the reduction part of the catalytic sequence, in which $\mathrm{C}-\mathrm{H}$ bonds are activated using lattice oxygen atoms.

\section{Conclusions}

The reactivity of supported $\mathrm{WO}_{x}$ domains in acid-catalyzed reactions depends sensitively on $\mathrm{WO}_{x}$ surface density, because of the electronic consequences of concurrent changes in domain size. Catalysts with intermediate $\mathrm{WO}_{x}$ surface densities gave the highest turnover rates (per $\mathrm{W}$ atom) for 2-butanol dehydration and $o$-xylene isomerization and the highest concentrations of $\mathrm{H}^{\delta+}\left(\mathrm{WO}_{x}\right)_{n}{ }^{\delta-}$ species acting as Brønsted acid sites. These species form via reduction and protonation of dispersed isopolytungstate domains by either $\mathrm{H}_{2}$ or alkanol reactants. Small domains prevalent at low $\mathrm{WO}_{x}$ surface densities cannot reduce to form these acid sites. Extended crystalline $\mathrm{WO}_{x}$ structures prevail at high $\mathrm{WO}_{x}$ surface densities. They give low Brønsted acid site densities (per W atom) because of their poor dispersion and their tendency to form oxygen-deficient domains, which cannot stabilize Brønsted acid sites. Brønsted acid site densities were higher when $\mathrm{WO}_{x}$ domains were supported on more reducible supports, but the intrinsic reactivity of these sites did not depend on support identity.

Keggin-type POM clusters are, in contrast to supported $\mathrm{WO}_{x}$ clusters, well-defined in size, atomic connectivity, and composition. These features combined with rigorous assessment of the mechanistic basis for their reactivity allow us to probe fundamental relations among composition, structure, and catalytic function. POM clusters with different central atoms ( $\mathrm{P}, \mathrm{Si}, \mathrm{Al}, \mathrm{Co})$ and zeolite $\mathrm{H}$-BEA gave alkanol dehydration and alkoxide isomerization rate constants that increased exponentially as POM deprotonation enthalpies (DPE) decreased and acid strength concurrently increased. These reactivity-DPE correlations allow assessments of acid strength and DPE values for Brønsted acids, such as $\mathrm{H}^{\delta+}\left(\mathrm{WO}_{3}\right)_{n}{ }^{\delta-}$ species, whose structures are incompletely understood and not amenable to simulations. DPE values and acid strength of these dispersed structures were determined by this method to be similar to those for acidic zeolites.

Alkane and alkanol oxidative dehydrogenation reactions on supported $\mathrm{MO}_{x}$ domains involve kinetically relevant $\mathrm{C}-\mathrm{H}$ bond breaking steps. These steps lead to the formal reduction 
of the metal centers in oxide domains and to marked effects of domain size, through their concomitant effects on electronic properties and reduction dynamics. Supported $\mathrm{MO}_{x}$ catalysts with different metal atoms $(\mathrm{V}, \mathrm{Mo}, \mathrm{W}, \mathrm{Nb})$, surface densities, and supports show a common increase in oxidative dehydrogenation turnover rates with decreasing energies for oxygento-metal charge transitions. These universal trends reflect a concurrent decrease in the activation barriers for kineticallyrelevant $\mathrm{C}-\mathrm{H}$ bond activation steps as the energy level of the lowest unoccupied states of the $\mathrm{MO}_{x}$ domains decreases. These unoccupied levels decrease in energy in the order $\mathrm{Nb}>\mathrm{W}>\mathrm{Mo}>\mathrm{V}$ and also as the size of the oxide domains and the reducibility of the support increase.

The general features determining the reactivity of $\mathrm{MO}_{x}$ based catalysts in acid and oxidation chemistries are more or less evident from these studies. The detailed understanding of the interplay of structure, composition, and the energies and entropies of intermediates and transition states in acid or oxidation elementary steps, which ultimately determine overall selectivities and rates, remains a challenge for all but a few simple reactions. Advances in our knowledge and in our ability to design inorganic structures for specific purposes will require a seamless combination of experiment and theory, the use of structurally well-defined clusters (e.g. Keggin-type POM clusters), and the interpretation of rate and selectivity data in terms of rate and equilibrium constants for elementary steps and of the specific structures of the adsorbed species and transition states responsible for the observed chemical transformations.

\section{Acknowledgements}

The authors acknowledge the technical and conceptual contributions of Drs. Chelsey D. Baertsch, David G. Barton, Morris D. Argyle, Kaidong Chen, Michael J. Janik, Matthew Neurock, Alexis T. Bell, and Stuart L. Soled to the concepts and findings described in this Perspective and in previous studies jointly published and cited herein. The financial support of the Office of Basic Energy Sciences, Chemical Sciences Division, U.S. Department of Energy under Contracts DE-AC03-76SF00098 and DE-FG02-03ER15479 and of the Division of Chemical and Transport Systems, National Science Foundation, under Grant CTS-9510575 for the work cited here is gratefully acknowledged. One of the authors (E.I.) is grateful for a Humboldt Senior Scientist Award from the Alexander von Humboldt Foundation, which provided support for a sabbatical leave during which parts of this article were redacted.

\section{References}

1 D. G. Barton, S. L. Soled, G. D. Meitzner, G. A. Fuentes and E. Iglesia, J. Catal., 1999, 181, 57.

2 D. G. Barton, M. Shtein, R. D. Wilson, S. L. Soled and E. Iglesia, J. Phys. Chem. B, 1999, 103, 630.

3 C. D. Baertsch, S. L. Soled and E. Iglesia, J. Phys. Chem. B, 2001, 105, 1320.

4 K. Chen, A. T. Bell and E. Iglesia, J. Catal., 2002, 209, 35.

5 K. Chen, A. T. Bell and E. Iglesia, J. Phys. Chem. B, 2000, 104, 1292.

6 A. Henglein, Ber. Bunsen-Ges. Phys. Chem., 1995, 99, 903.
7 A. Zunger, Mater. Res. Soc. Bull., 1998, 35.

8 A. P. Alivisatos, Science, 1996, 271, 933.

9 D. G. Barton, S. L. Soled and E. Iglesia, Top. Catal., 1988, 6, 87.

10 C. D. Baertsch, K. T. Komala, Y. H. Chua and E. Iglesia, J. Catal., 2002, 205, 44.

11 K. Chen, A. Khodakov, J. Yang, A. T. Bell and E. Iglesia, J. Catal., 1999, 186, 325.

12 K. Chen, S. Xie, E. Iglesia and A. T. Bell, J. Catal., 2000, 189, 421.

13 M. G. White, Catal. Today, 1993, 18(1), 73.

14 V. Kazansky, Catal. Today, 2002, 73, 127.

15 M. Hino and K. Arata, Chem. Commun., 1998, 1259; K. Arata and M. Hino, Proceedings of the 9th International Congress on Catalysis, ed. M. H. Phillips and M. Ternan, The Chemical Institute of Canada, Ottawa, 1988, p. 1727; M. Hino and K. Arata, Appl. Catal. A: Gen., 1988, 169, 151.

16 G. Larsen and L. Petkovic, J. Mol. Catal. A: Chem., 1996, 113, 517.

17 J. G. Santiesteban, J. Vartuli, S. Han, R. Bastian and C. D. Chang, J. Catal., 1997, 168, 431.

18 S. Kuba, R. K. Grasselli, H. Knözinger and B. C. Gates, Chem. Commun., 2001, 321; M. Scheithauer, T.-K. Cheung, R. E. Jentoft, R. K. Grasselli, B. C. Gates and H. Knözinger, J. Catal., 1998, $180,1$.

19 Proceedings 11th International Congress of Catalysis, ed. J. W. Hightower, W. N. Delgass, E. Iglesia and A. T. Bell, Elsevier, AmsterdamE. Iglesia, D. G. Barton, S. L. Soled, S. Miseo, J. E. Baumgartner, W. G. Gates, G. A. Fuentes and G. D. Meitzner, Stud. Surf. Sci. Catal., 1996, 101, 533.

20 A. Cortes and A. Corma, J. Catal., 1978, 51, 338.

21 S. Morin, N. S. Gnep and M. Guisnet, J. Catal., 1996, 159, 296.

22 R. S. Weber, J. Catal., 1995, 151, 470.

23 M. Fournier, C. Louis, M. Che, P. Chaquin and P. Masure, J. Catal., 1989, 119, 400.

24 Y. Wang and N. Herron, J. Phys. Chem., 1991, 91, 525.

25 L. E. Brus, J. Chem. Phys., 1984, 80, 4403.

26 D. Masure, P. Chaquin, C. Louis, M. Che and M. Fournier, J. Catal., 1989, 119, 415.

27 H. Knözinger and R. Kohne, J. Catal., 1966, 5, 264.

28 H. Knözinger, H. Buhl and K. Kochloefl, J. Catal., 1972, 24, 57.

29 B. H. Davis, J. Catal., 1978, 55, 158.

30 P. Berteau and B. Delmon, Appl. Catal., 1991, 70, 307.

31 H. Knözinger and A. Scheglila, J. Catal., 1970, 17, 252.

32 S. Soled, G. B. McVicker, L. Murrell, L. Sherman, N. Dispenziere, S. Hsu and D. Waldman, J. Catal., 1988, 111, 286.

33 J. Macht, C. D. Baertsch, M. May-Lozano, S. L. Soled, Y. Wang and E. Iglesia, J. Catal., 2004, 227, 479.

34 K. Xiong, J. Robertson and S. J. Clark, J. Appl. Phys., 2007, 102, 083710 .

35 J. Macht, M. J. Janik, M. Neurock and E. Iglesia, Angew. Chem., Int. Ed., 2007, 46, 7864.

36 M. Brändle and J. Sauer, J. Am. Chem. Soc., 1998, 120, 1556.

37 M. J. Janik, K. A. Campbell, B. B. Bardin, R. J. Davis and M. Neurock, Appl. Catal., A, 2003, 256, 51.

38 J. Macht, M. J. Janik, M. Neurock and E. Iglesia, J. Am. Chem. Soc., 2008, accepted.

39 A. L. L. East, T. Bucko and J. Hafner, J. Phys. Chem. A, 2007, 111(27), 5945.

$40 \mathrm{~J}$. Macht andE. Iglesia, unpublished results.

41 H. Liu, P. Cheung and E. Iglesia, J. Phys. Chem. B, 2003, 107, 4118.

42 H. Liu, P. Cheung and E. Iglesia, Phys. Chem. Chem. Phys., 2003, 5, 3795 .

43 H. Liu and E. Iglesia, J. Phys. Chem. B, 2005, 109, 2155.

44 J. Lichtenberger, D. Lee and E. Iglesia, Phys. Chem. Chem. Phys., 2007, 9, 4902.

45 K. Chen, S. Xie, A. T. Bell and E. Iglesia, J. Catal., 2001, 198, 232.

46 M. D. Argyle, K. Chen, A. T. Bell and E. Iglesia, J. Phys. Chem. B, $2002,106,5421$.

47 M. D. Argyle, K. Chen, A. T. Bell and E. Iglesia, J. Catal., 2002, 208, 139.

48 K. Chen, A. T. Bell and E. Iglesia, Stud. Surf. Sci. Catal., 2001, 136, 507.

49 P. Mars and D. W. van Krevelen, Chem. Eng. Sci., 1954, 3(Special Suppl.), 41.

50 M. D. Argyle, K. Chen, C. Resini, C. Krebs, A. T. Bell and E. Iglesia, J. Phys. Chem. B, 2004, 108, 2345. 